\title{
Effects of vitro sucrose on quality components of tea plants (Camellia sinensis) based on transcriptomic and metabolic analysis
}

Yumei Qian ${ }^{1,2 \dagger}$, Shuxiang Zhang ${ }^{3 \dagger}$, Shengbo Yao ${ }^{1 \dagger}$, Jinxin Xia ${ }^{3}$, Yanzhi $\mathrm{Li}^{1}$, Xinlong Dai ${ }^{1}$, Wenzhao Wang ${ }^{1}$, Xiaolan Jiang ${ }^{1}$, Yajun Liu', Mingzhuo Li', Liping Gao ${ }^{3 *}$ and Tao Xia ${ }^{{ }^{3 *}}$

\begin{abstract}
Background: Tea plants [Camellia sinensis (L.) O. Kuntze] can produce one of the three most widely popular nonalcoholic beverages throughout the world. Polyphenols and volatiles are the main functional ingredients determining tea's quality and flavor; however, the biotic or abiotic factors affecting tea polyphenol biosynthesis are unclear. This paper focuses on the molecular mechanisms of sucrose on polyphenol biosynthesis and volatile composition variation in tea plants.

Results: Metabolic analysis showed that the total content of anthocyanins, catechins, and proanthocyanidins(PAs) increased with sucrose, and they accumulated most significantly after 14 days of treatment. Transcriptomic analysis revealed 8384 and 5571 differentially expressed genes in 2-day and 14-day sucrose-treated tea plants compared with control-treated plants. Most of the structural genes and transcription factors (TFs) involved in polyphenol biosynthesis were significantly up-regulated after $2 \mathrm{~d}$. Among these transcripts, the predicted genes encoding glutathione S-transferase (GST), ATP-binding cassette transporters (ABC transporters), and multidrug and toxic compound extrusion transporters (MATE transporters) appeared up regulated. Correspondingly, ultra-performance liquid chromatography-triple quadrupole mass spectrometry (UPLC-QQQ-MS/MS) analysis revealed that the content of non-galloylated catechins and oligomeric PAs decreased in the upper-stem and increased in the lower-stem significantly, especially catechin (C), epicatechin (EC), and their oligomeric PAs. This result suggests that the related flavonoids were transported downward in the stem by transporters. GC/MS data implied that four types of volatile compounds, namely terpene derivatives, aromatic derivatives, lipid derivatives, and others, were accumulated differently after in vitro sucrose treatment.

Conclusions: Our data demonstrated that sucrose regulates polyphenol biosynthesis in Camellia sinensis by altering the expression of transcription factor genes and pathway genes. Additionally, sucrose promotes the transport of polyphenols and changes the aroma composition in tea plant.
\end{abstract}

Keywords: Camellia sinensis, Polyphenol biosynthesis, Volatile, Sucrose induction, Transcriptomic and metabolic analysis

\footnotetext{
*Correspondence: gaolp62@126.com; xiatao62@126.com

${ }^{\dagger}$ Yumei Qian, Shuxiang Zhang and Shengbo Yao contributed equally to this work.

${ }^{3}$ School of Life Science, Anhui Agricultural University, 130 West Changjiang Rd, Hefei 230036, Anhui, China

'State Key Laboratory of Tea Plant Biology and Utilization, Anhui Agricultural

University, 130 West Changjiang Rd, Hefei 230036, Anhui, China

Full list of author information is available at the end of the article
}

(c) The Author(s). 2018 Open Access This article is distributed under the terms of the Creative Commons Attribution 4.0 International License (http://creativecommons.org/licenses/by/4.0/), which permits unrestricted use, distribution, and reproduction in any medium, provided you give appropriate credit to the original author(s) and the source, provide a link to the Creative Commons license, and indicate if changes were made. The Creative Commons Public Domain Dedication waiver (http://creativecommons.org/publicdomain/zero/1.0/) applies to the data made available in this article, unless otherwise stated. 


\section{Background}

The tea plant [Camellia sinensis (L.) O. Kuntze] is one of the most important economic crops cultivated in China, Japan, India, and other countries. Its leaves are used for making the tea beverage, one of three most widely consumed non-alcoholic beverages around the world because it contains abundant polyphenols, theanine, caffeine, and other secondary metabolites [1]. Among them, the polyphenol, also called tea polyphenol, is a collective term for phenolic acids and flavonoids including flavanols (catechins), anthocyanins, PAs (also named condensed tannins), and other special derivatives. Polyphenols account for $18-36 \%$ of the dry weight of tender leaves and are responsible for tea's flavor [2-4]. Some studies have suggested that polyphenols play crucial roles in plant stress resistance. For example, they are crucial for protecting the tea plant against pathogens and insects $[5,6]$. Additionally, polyphenols are the main functional ingredient in tea for preventing cancer, cardiovascular diseases, and obesity [7].

Studies have indicated that polyphenol biosynthesis in plants is influenced by chemical and physical factors, such as nutrients, hormones, and environmental conditions [8-13]. Among them, sucrose acts not only as carbon source for energy storage and sugar transportation, but also as a signal involved in metabolic processes such as anthocyanin synthesis in plants [14, 15]. Since the late twentieth century, the effects of sucrose on flavonoid and anthocyanin biosynthesis in grapes and radishes have been studied [16-18]. In Arabidopsis thaliana, sucrose induces anthocyanin biosynthesis through the upregulation of structural genes and positive transcription factors involved in the flavonoid biosynthesis pathway and potentially also through the concurrent down-regulation of the negative transcription factor, MYB-LIKE 2 (MYBL2) [19-21]. Previous studies also reported that sucrose could act as a signaling molecule, by first activating PRODUCTION OF ANTHOCYANIN PIGMENT 1 (PAP1) expression by a sucrose-specific signaling pathway and then triggering the expression of structural genes involved in anthocyanin and flavonoid biosynthesis $[14,19,22,23]$. The sucrose-specific signaling pathway may be activated by different disaccharides, such as sucrose, maltose, and their breakdown products (glucose and fructose); however, sucrose is the most effective inducer of anthocyanin biosynthesis in Arabidopsis [23]. Liu et al. reported sucrose induction increases the content of non-galloylated catechins and up-regulates the expression of putative genes involved in their biosynthetic pathway in both tea callus and seedling [24]. Additionally, Wang et al. also reported sucrose up-regulates the expression of Camellia SINENSIS FLAVONOID 3'5'-HYDROXYLASE (CsF3'5'H), an important branch point gene involved in catechins biosynthesis
[25]. In this study, test-tube tea plantlets were used to test for testing the effects of sucrose on polyphenol biosynthesis after $2,7,14$, and $28 \mathrm{~d}$ treatments. The results indicated that sucrose can increase the expression of structural genes involved in the biosynthesis of anthocyanins, catechins, and procyanidins. The sucrose specific induction machenism in tea plant is still unclear, one important reason is that we lack the information supported by accurate genome annotations.

Next-Generation Sequencing (NGS) based on the Illumina Hiseq 2000 platform provides a fast, cost-effective, and reliable approach to acquire abundant transcripts, especially for non-model organisms without reference genomic sequences [26]. In tea plants, the NGS technology has been used for analysis of putative genes associated with tea quality and stress response [27-29]. Here, it was performed to investigate the molecular mechanism of sucrose on polyphenol biosynthesis in tea plants and to provide a comprehensive analysis of the network of biochemical and cellular processes responding to sucrose.

In addition, we determined whether in vitro sucrose treatment affects the production of volatiles-the second group of compounds that affect tea taste and flavor in addition to polyphenols.

\section{Results}

Effects of sucrose on polyphenol accumulation

Similar sized test-tube tea plantlets were cultured on Murashige and Skoog standard medium (MS, Control) and MS supplemented with $90 \mathrm{mM}$ sucrose (MS + $90 \mathrm{mM}$ sucrose, Suc) for 28d (Fig. 1a). The stem of the plantlets grown on Suc for 9-14d began to turn red (Fig. 1b), while no red pigmentation was observed in the stem of the plantlets grown on MS or MS supplemented with $90 \mathrm{mM}$ mannitol (data not shown). The anthocyanin levels were significantly different only in the lower part of the stem and were 7 -fold higher than that in the control (Fig. 1c). Furthermore, the accumulation of total catechins and PAs in various organs of tea plants is affected by sucrose (Fig. 1d). The effects of sucrose treatment on polyphenol accumulation were observed after 7 and 14 days of treatment (Fig. 1d). However, the effects of sucrose on total catechins and PAs accumulation were not observed at $2 \mathrm{~d}$ treatment (data not shown).

Polyphenol, including phenolic acids, catechin monomers, oligomeric PAs, and flavonols, in different tissues of tea plantlets after 14d treatment was quantitatively measured using UPLC-QQQ-MS/MS (Table 1). Three types of phenolic acids were measured, including quinic acid, gallic acid derivatives ( $\beta$-glucogallin, galloyl acid and galloylquinic acid), and hydroxycinnamic acid derivatives (caffeoylquinic acid and p-coumaroylquinic acid). The effect of sucrose on compound accumulation was 
$\mathbf{a}$

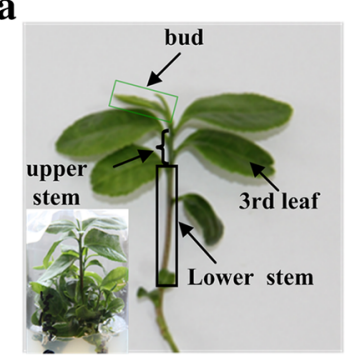

b

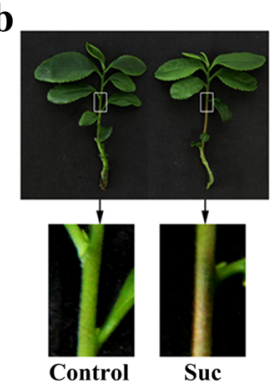

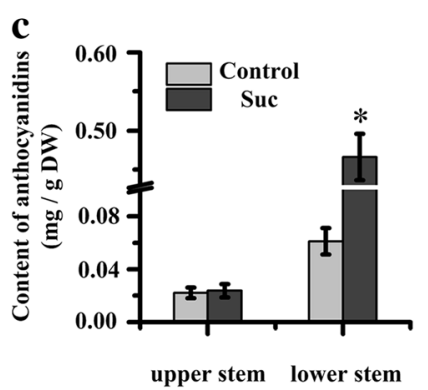

d
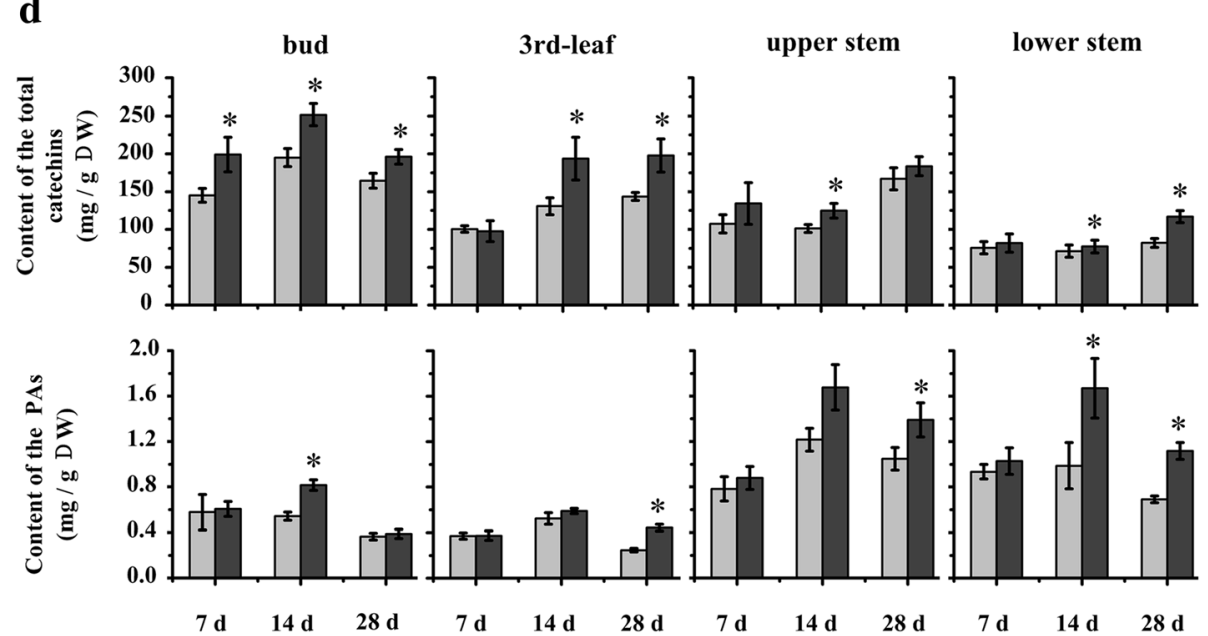

Fig. 1 Effects of sucrose on polyphenol accumulation in test-tube tea plantlets. $\mathbf{a}$. Test-tube tea plantlets; $\mathbf{b}$. Red pigments accumulated in stems of plantlet after feeding sucrose; c. Anthocyanin levels are significantly different in the lower part of the stem; $\mathbf{d}$. Accumulation of total catechins and PAs in various organs after 7, 14 and $28 \mathrm{~d}$ sucrose treatment. Note: ${ }^{*}$ indicates significance at $P<0.05$. The data represents the mean value of three biological replicates

different. For example, sucrose increased the content of galloylquinic acid, a special phenolic acid in the tea plant, increased in most parts of the plants, except for in the bud. However, the content of $\beta$-glucogallin, the precursor of galloylated catechins, significantly decreased by $84 \%$ in buds and by $71 \%$ in upper stems [30]. Monomers of flavanols (catechins) can be classified into non-galloylated and galloylated catechins and mainly exist in buds and upper stems. More non-galloylated catechins accumulated in buds and lower stems after sucrose treatment; however, their content in upper stems decreased significantly. Catechin (C) and epicatechin (EC) decreased by $69 \%$ in upper stems. The galloylated catechin content in buds and lower stems was not affected by sucrose, and its content in the 3rd leaf and upper stem decreased by $19 \%$. Seven types of oligomeric PAs accumulated in the bud and 3rd leaf. Their content in lower stems increased 3-fold. However, their content in upper stems significantly decreased after sucrose treatment. For example, B2 (an oligomeric C or EC), decreased by $81 \%$. The content of flavonols in the tea plant was also affected by sucrose. Among them, the flavonol with di-hydroxyl groups on the B-ring was significantly affected by sucrose, and its amount decreased by almost $40 \%$ in the third leaf and upper stems and by $14 \%$ in buds. However, its content increased by 1 -fold in the lower stem.

\section{Effects of sucrose on volatile compounds}

Four types of volatile compounds were measured using $\mathrm{GC} / \mathrm{MS}$, including terpene derivatives, aromatic derivatives, lipid derivative and other compounds, the effect of sucrose on their accumulation was different (see Additional file 1: Table S1). For example, the content of $\alpha$-farnesene belonging to sesquiterpenoid diterpenoid increased 5.77-fold; the expression of one transcript (Unigene 46,443), which was predicted as the key biosynthetic gene encoding farnesene synthase, was significantly upregulated 3-fold after 2 and 14 days of sucrose treatment (see Additional file 2: Table S2). Here, 33 terpene derivatives were detected and classified into monoterpenoid sesquiterpenoid diterpenoid; these compounds were biosynthesized via methylerythritol phosphate (MEP) and mevalonate (MVA) pathways (see Additional file 3: Figure S1). The expression of HMGR (CL12062.Contig1) and DXS (Unigene57617) and DXR (Unigene46601) as the key genes involving in terpenoid 


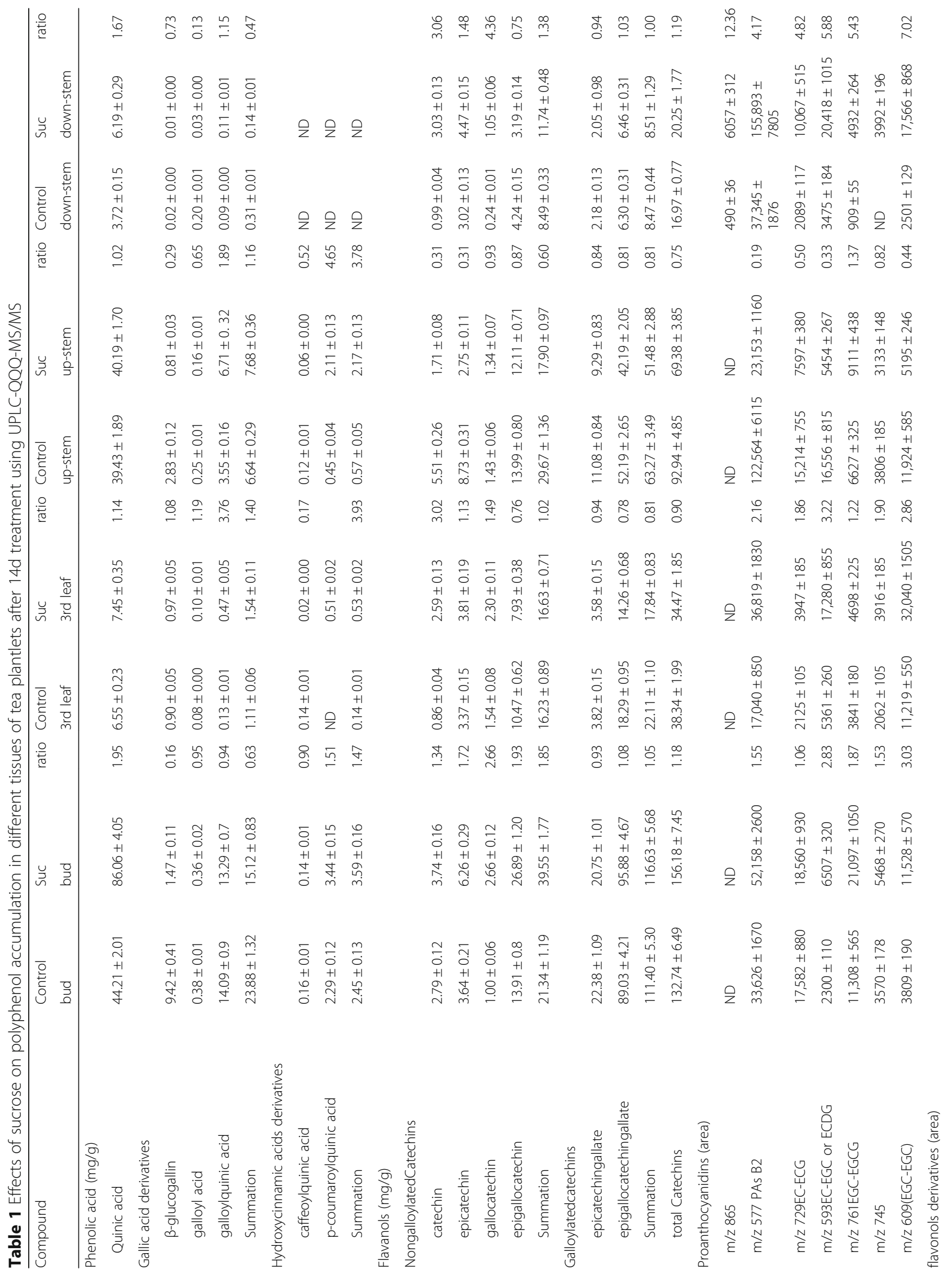


Qian et al. BMC Plant Biology (2018) 18:121

Page 5 of 20

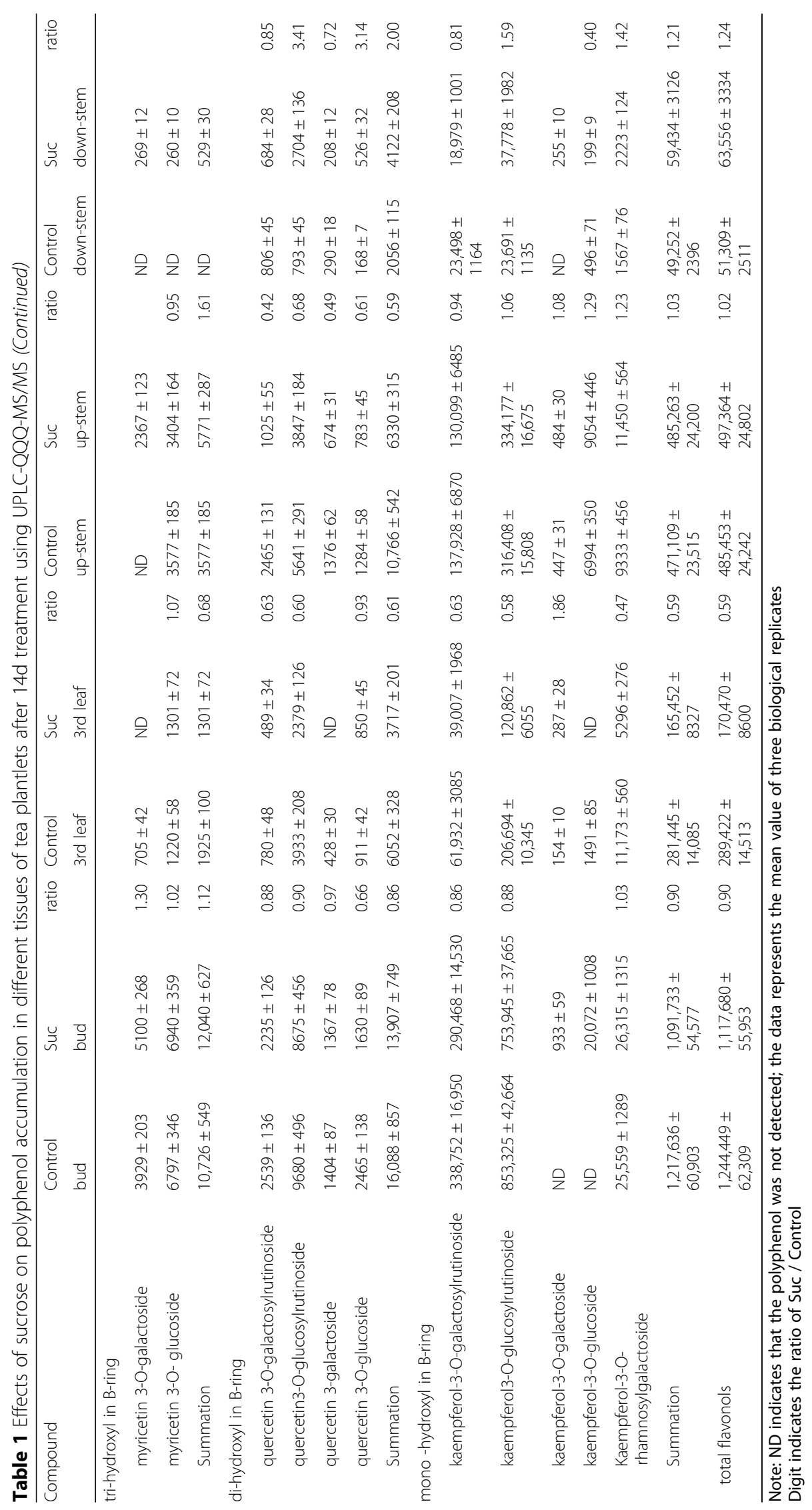


backbone pathway were up-regulated by sucrose. The expression of one transcript (CL1850.Contig3 encoding linalool synthase) was not significantly affected by sucrose; and the content of linalool and geraniol in tea leaf only decreased by $4 \%$. Additionally, the expression of 1 transcript (Unigene9305 encoding (E)-nerolidol synthase) was up-regulated by sucrose after $2 \mathrm{~d}$; however, its expression was down- regulated by sucrose after $14 \mathrm{~d}$; and the content of the (E)-nerolidol only decreased by $5 \%$.

\section{Effects of sucrose on the expression of key structural} genes related to polyphenol biosynthesis using qRT-PCR For further analysis of the effects of sucrose on polyphenol biosynthesis at the transcriptional level, Quantitative real-time-PCR (qRT-PCR) was used to test the expression of 11 key structural genes involved in the polyphenol biosynthetic pathway (Fig. 2). Their expression significantly increased 3-fold after $2 \mathrm{~d}$ treatment. After $7 \mathrm{~d}$, the expression of Chalcone synthase (CHS), Flavanone 3-hydroxylase $(\mathrm{F} 3 \mathrm{H})$, Flavonoid 3'-hydroxylase $\left(\mathrm{F} 3{ }^{\prime} \mathrm{H}\right)$, Leucoanthocyanidin reductase (LAR), and Anthocyanidin reductase (ANR) increased 1-fold. After 14d, the effect of sucrose on the above genes was less noticeable.

\section{Sequencing, de novo assembly, and functional annotation} To obtain the overall transcriptional levels of genes in the tea plant treated by sucrose after 2 and $14 \mathrm{~d}$, four normalized cDNA libraries (2d: 2nd D Control and Suc; 14d: 14th D Control and Suc) were constructed for transcriptome sequencing. Based on the Illumina Hiseq 2000 platform, 21,381,193,620 nucleotide (nt) bases were generated from all libraries in total and about 237.6 million clean reads ( $94.94 \%$ of the raw reads) were achieved for de novo assembly (see Additional file 4: Table S3). Finally, a total of 118,843 transcripts were obtained with an average length of $1212 \mathrm{nt}$ and a N50 of $1999 \mathrm{nt}$ (see Additional file 5: Table S4).

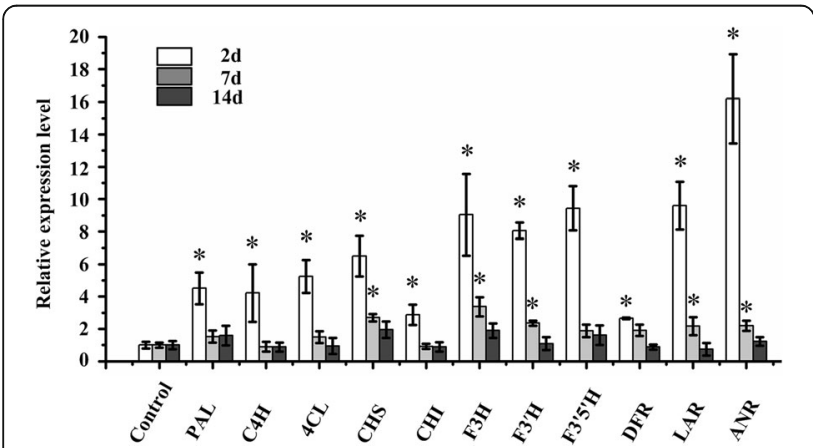

Fig. 2 Effects of sucrose on expression of key structural genes involved in polyphenol biosynthesis using qRT-PCR. Note: * indicates significance with $\mid \log 2$ Ratio $\mid \geq 1$. The data represents the mean value of three biological and three technical replicates
To predict the functions of the assembly transcripts, a total of 82,459 transcripts $(69.38 \%$ of all assembled Unigenes) were annotated using the NR (Non-redundant protein database), NT (Non-redundant nucleotide database), Swiss-Prot (Annotated protein sequence database), KEGG (Kyoto encyclopedia of genes and genomes), COG (Clusters of orthologous groups of protein), and GO (Gene ontology) databases based on two levels of sequence similarity, sequence-based and domain-based alignments, with an e-value $<1$ e-5 (see Additional file 6: Table S5).

\section{Analysis of DEGs responding to sucrose}

Using the fragments per kb per million reads (FPKM) method, the DEGs between two samples were identified with a significant threshold of $\mid \log 2$ Ratio (FPKM Control-vs-Suc) $\mid \geq 1$ and the false discovery rate (FDR) of $\leq 0.001$ based on the $P$-value threshold set as $\leq 1 \mathrm{e}-5$. A total of 8384 DEGs were detected in 2nd D Control-vs-Suc. Among them, 6187 DEGs (73.80\% of the total DEGs) were up-regulated. A total of 5571 DEGs were detected in 14th D Control-vs-Suc, and only 2146 DEGs $(38.52 \%$ of the total DEGs) were up-regulated (see Fig. 3).

\section{GO function and KEGG pathways analysis of DEGs responding to sucrose}

To better understand the biological functions of DEGs responding to sucrose, GO and KEGG analyses were performed for comparisons of 2nd D Control-vs-Suc and 14th D Control-vs-Suc. GO functional enrichment analysis indicated that 49 and 48 GO terms were classified into three ontologies which changed significantly between

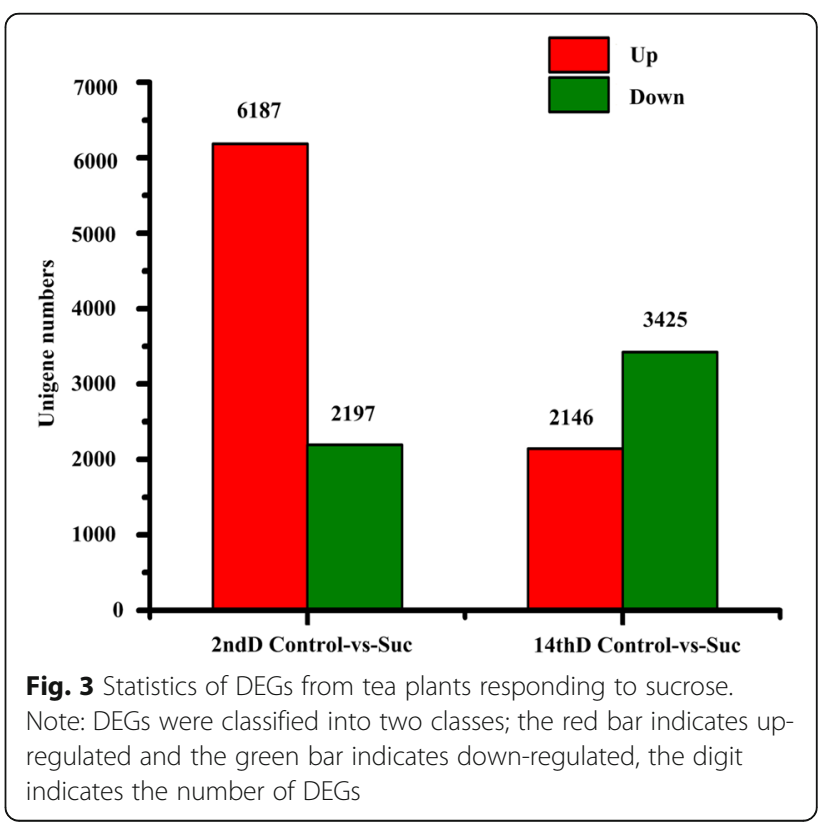


Table 2 Gene ontology analysis of DEGs obtained from tea plants treated by sucrose after $2 d$

\begin{tabular}{|c|c|c|c|c|}
\hline & Pathway & $\begin{array}{l}\text { DEGs genes } \\
\text { (3553) }\end{array}$ & $\begin{array}{l}\text { All genes } \\
(47655)\end{array}$ & Q-value \\
\hline 1 & Flavonoid biosynthesis & $87(2.45 \%)$ & $314(0.66 \%)$ & $2.35 \mathrm{E}-25$ \\
\hline 2 & Biosynthesis of secondary metabolites & $530(14.92 \%)$ & $4746(9.96 \%)$ & $1.33 \mathrm{E}-20$ \\
\hline 3 & Phenylpropanoid biosynthesis & $124(3.49 \%)$ & $653(1.37 \%)$ & $1.76 \mathrm{E}-20$ \\
\hline 4 & Stilbenoid, diarylheptanoid and gingerol biosynthesis & $63(1.77 \%)$ & $233(0.49 \%)$ & $3.38 \mathrm{E}-18$ \\
\hline 5 & Flavone and flavonol biosynthesis & $44(1.24 \%)$ & $165(0.35 \%)$ & $1.41 \mathrm{E}-12$ \\
\hline 6 & Phenylalanine metabolism & $52(1.46 \%)$ & $234(0.49 \%)$ & $1.76 \mathrm{E}-11$ \\
\hline 7 & Plant hormone signal transduction & $291(8.19 \%)$ & $2615(5.49 \%)$ & $4.76 \mathrm{E}-11$ \\
\hline 8 & Zeatin biosynthesis & $63(1.77 \%)$ & $365(0.77 \%)$ & $5.88 \mathrm{E}-09$ \\
\hline 9 & Cutin, suberine and wax biosynthesis & $30(0.84 \%)$ & $116(0.24 \%)$ & 1.65E-08 \\
\hline 10 & Pentose and glucuronateinterconversions & $70(1.97 \%)$ & $452(0.95 \%)$ & $6.26 \mathrm{E}-08$ \\
\hline 11 & DNA replication & $44(1.24 \%)$ & $244(0.51 \%)$ & 4.79E-07 \\
\hline 12 & Carotenoid biosynthesis & $40(1.13 \%)$ & $212(0.44 \%)$ & 4.95E-07 \\
\hline 13 & Limonene and pinene degradation & $34(0.96 \%)$ & $170(0.36 \%)$ & 1.05E-06 \\
\hline 14 & Metabolic pathways & $902(25.39 \%)$ & $10,454(21.94 \%)$ & 1.79E-06 \\
\hline 15 & Ether lipid metabolism & $130(3.66 \%)$ & $1142(2.4 \%)$ & 8.47E-06 \\
\hline 16 & Starch and sucrose metabolism & $129(3.63 \%)$ & $1141(2.39 \%)$ & 1.24E-05 \\
\hline 17 & Diterpenoid biosynthesis & $22(0.62 \%)$ & $105(0.22 \%)$ & $6.04 \mathrm{E}-05$ \\
\hline 18 & Tryptophan metabolism & $22(0.62 \%)$ & $107(0.22 \%)$ & 7.84E-05 \\
\hline 19 & Other glycan degradation & $47(1.32 \%)$ & $328(0.69 \%)$ & 8.46E-05 \\
\hline 20 & Endocytosis & $156(4.39 \%)$ & $1526(3.2 \%)$ & 2.40E-04 \\
\hline 21 & Glycerophospholipid metabolism & $160(4.5 \%)$ & 1577 (3.31\%) & 2.69E-04 \\
\hline 22 & Glucosinolate biosynthesis & $15(0.42 \%)$ & $64(0.13 \%)$ & $3.18 \mathrm{E}-04$ \\
\hline 23 & Isoflavonoid biosynthesis & $15(0.42 \%)$ & $72(0.15 \%)$ & $1.25 \mathrm{E}-03$ \\
\hline 24 & Plant-pathogen interaction & 309 (8.7\%) & $3440(7.22 \%)$ & $1.60 \mathrm{E}-03$ \\
\hline 25 & Monoterpenoid biosynthesis & $10(0.28 \%)$ & $41(0.09 \%)$ & $3.38 \mathrm{E}-03$ \\
\hline 26 & Anthocyanin biosynthesis & $6(0.17 \%)$ & $20(0.04 \%)$ & $1.26 \mathrm{E}-02$ \\
\hline 27 & Cysteine and methionine metabolism & $40(1.13 \%)$ & $339(0.71 \%)$ & 1.27E-02 \\
\hline 28 & Base excision repair & $29(0.82 \%)$ & $228(0.48 \%)$ & $1.51 \mathrm{E}-02$ \\
\hline 29 & Homologous recombination & $36(1.01 \%)$ & $323(0.68 \%)$ & 4.46E-02 \\
\hline
\end{tabular}

2nd D and 14th D Control-vs-Suc (see Additional file 7: Figure S2).

A total of 3553 DEGs $(7.46 \%$ of all the transcripts aligned to the KEGG database) were annotated and 29 KEGG pathways were enriched significantly in the 2nd D Control-vs-Suc comparison based on a Q-value of $\leq 0.05$. Among them, the most enriched pathway was "flavonoid biosynthesis" (Table 2). In 14th D Control-vs-Suc comparison, 2009 DEGs $(4.22 \%$ of all the transcripts aligned to KEGG databases) were annotated and 20 KEGG pathways were significantly enriched with the same threshold. The most enriched pathway was that for "plant-pathogen interaction" (Table 3). A total of 17 KEGG-enriched pathways were common between second and fourteenth D Control-vs-Suc. Of the 12 KEGG pathways specific to the second D Control-vs-Suc comparison, one was the KEGG-enriched pathway for anthocyanin biosynthesis (Fig. 4).

\section{Effects of sucrose on polyphenol biosynthesis based on transcriptome sequencing}

Based on the ratio of FPKM Control-vs-Suc, most of the transcripts involved in the phenylpropanoid and flavonoid pathways were up-regulated 2-fold or more after $2 \mathrm{~d}$ of treatment. Additionally, the expression of transcripts annotated as Phenylalanine ammonialyase (PAL), Dihydroflavonol 4-reductase (DFR), LAR, and Anthocyanidin synthase (ANS) was notably up-regulated. After 14 days of treatment, the expression of only PALB increased 1 -fold, whereas others were not affected by sucrose (Fig. 5). These results indicate that tea polyphenol biosynthesis is comprehensively affected by sucrose. 
Table 3 Gene Ontology analysis of DEGs obtained from tea plants treated by sucrose after 14d

\begin{tabular}{|c|c|c|c|c|}
\hline & \multirow[t]{2}{*}{ Pathway } & \multirow{2}{*}{$\begin{array}{l}\text { DEGs genes } \\
(2009)\end{array}$} & \multirow{2}{*}{$\begin{array}{l}\text { All genes } \\
(47655)\end{array}$} & \multirow[t]{2}{*}{ Q-value } \\
\hline & & & & \\
\hline 1 & Plant-pathogen interaction & $275(13.69 \%)$ & $3440(7.22 \%)$ & $3.78 \mathrm{E}-23$ \\
\hline 2 & Phenylpropanoid biosynthesis & $64(3.19 \%)$ & $653(1.37 \%)$ & $3.04 \mathrm{E}-08$ \\
\hline 3 & Zeatin biosynthesis & $41(2.04 \%)$ & $365(0.77 \%)$ & $6.03 \mathrm{E}-07$ \\
\hline 4 & Flavonoid biosynthesis & 37 (1.84\%) & $314(0.66 \%)$ & $6.41 \mathrm{E}-07$ \\
\hline 5 & Plant hormone signal transduction & 159 (7.91\%) & $2615(5.49 \%)$ & $5.74 \mathrm{E}-05$ \\
\hline 6 & Stilbenoid, diarylheptanoid and gingerol biosynthesis & $26(1.29 \%)$ & $233(0.49 \%)$ & 1.37E-04 \\
\hline 7 & Biosynthesis of secondary metabolites & $256(12.74 \%)$ & $4746(9.96 \%)$ & 3.87E-04 \\
\hline 8 & Diterpenoid biosynthesis & $15(0.75 \%)$ & $105(0.22 \%)$ & $5.25 \mathrm{E}-04$ \\
\hline 9 & Glycerophospholipid metabolism & $96(4.78 \%)$ & $1577(3.31 \%)$ & $3.06 \mathrm{E}-03$ \\
\hline 10 & DNA replication & $23(1.14 \%)$ & $244(0.51 \%)$ & $3.55 \mathrm{E}-03$ \\
\hline 11 & Phenylalanine metabolism & $22(1.1 \%)$ & $234(0.49 \%)$ & 4.47E-03 \\
\hline 12 & alpha-Linolenic acid metabolism & $17(0.85 \%)$ & $164(0.34 \%)$ & $5.98 \mathrm{E}-03$ \\
\hline 13 & Starch and sucrose metabolism & $71(3.53 \%)$ & $1141(2.39 \%)$ & $7.18 \mathrm{E}-03$ \\
\hline 14 & Isoflavonoid biosynthesis & $10(0.5 \%)$ & $72(0.15 \%)$ & $7.18 \mathrm{E}-03$ \\
\hline 15 & Limonene and pinene degradation & $17(0.85 \%)$ & $170(0.36 \%)$ & 7.18E-03 \\
\hline 16 & Monoterpenoid biosynthesis & $7(0.35 \%)$ & $41(0.09 \%)$ & $1.12 \mathrm{E}-02$ \\
\hline 17 & Ether lipid metabolism & $69(3.43 \%)$ & $1142(2.4 \%)$ & $1.39 \mathrm{E}-02$ \\
\hline 18 & Nitrogen metabolism & $18(0.9 \%)$ & $203(0.43 \%)$ & $1.68 \mathrm{E}-02$ \\
\hline 19 & Phosphatidylinositol signaling system & $33(1.64 \%)$ & $465(0.98 \%)$ & $1.74 \mathrm{E}-02$ \\
\hline 20 & Flavone and flavonol biosynthesis & $15(0.75 \%)$ & $165(0.35 \%)$ & $2.62 \mathrm{E}-02$ \\
\hline
\end{tabular}

Effects of sucrose on the expression of transcription factors involved in polyphenol biosynthesis based on transcriptome sequencing

Polyphenol biosynthesis in plants is regulated by transcription factors (TFs) including R2R3-MYB, bHLH, and WD40 [31, 32]. In this study, 37 DEGs were predicted to be MYB members and were classified into three types: R1 (4 DEGs), R2R3 (29 DEGs), and R1R2R3 (4 DEGs). Most DEGs (23/37) were up-regulated after sucrose treatment for 2 days, and only five DEGs were up-regulated after sucrose treatment for 14 days (Table 4). Additionally, the phylogenetic tree, including 29 R2R3-MYBs and 126 Arabidopsis R2R3-MYBs, were classified into 13 subgroups (see Additional file 8: Figure S3). Phylogenetic analysis indicated that 33 bHLHs were dispersed into 15 subfamilies (see Additional file 9: Figure S4), and 21 of them were up-regulated after sucrose treatment for $2 \mathrm{~d}$ (Table 5).

The R2R3-MYBs, bHLH, and WD40 TFs, could act as regulators of polyphenol biosynthesis individually or jointly. The R2R3-MYBs in Subgroup (Sg) 4 and Sg7 were predicted to be negative and positive regulators, respectively, for controlling the production of flavonols via regulating the up-stream genes involved in polyphenol biosynthetic pathway [33, 34]. However, the R2R3-MYBs in Sg5 and Sg6 require both bHLH (subfamily 2, 5, and 24) and WD40 for construction into a ternary complex
MYB-bHLH-WD40 (MBW) for positively regulating down-stream genes involved in polyphenol biosynthetic pathway [31, 35, 36]. Here, 7 DEGs were classified into the above mentioned 4 subgroups of R2R3-MYBs. After $2 \mathrm{~d}$ sucrose treatment, the expression of 3 DEGs (Unigene12085, Unigene 41,846 and CL8695 Contig1) in Sg6 and Sg5 were significantly up-regulated 6-fold; and the expression of CL13057.Contig2 in Sg4 was down-regulated significantly (Fig. 6a). Additionally, 2 DEGs (Unigene 21,617, Unigene 5385) in Subfamily 5 of bHLHs were up-regulated by sucrose (Fig. 6b). Based on the same method, only one transcript (Unigene25483) was predicted to be involved in the MBW complex, and its expression was not affected by sucrose (Fig. 6c).

\section{Effects of sucrose on the expression of genes involved in} polyphenol transport

In plants, transporters (ABCs and MATEs), and GSTs are involved in polyphenol transporting. These transporters are found in many species including Arabidopsis TT19 and TT12 genes (AtTT19; AtTT12), the grape GST and ABCC1 genes (VvGST19; VvABCC1), the maize MRP3 gene (ZmMRP3), and the Medicago truncatula MATE (MtMATE) [37-42]. In the present study, 22, 15, and 21 DEGs were predicted to encode GST, $\mathrm{ABC}$, and MATE-transporters, respectively. Phylogenetic 


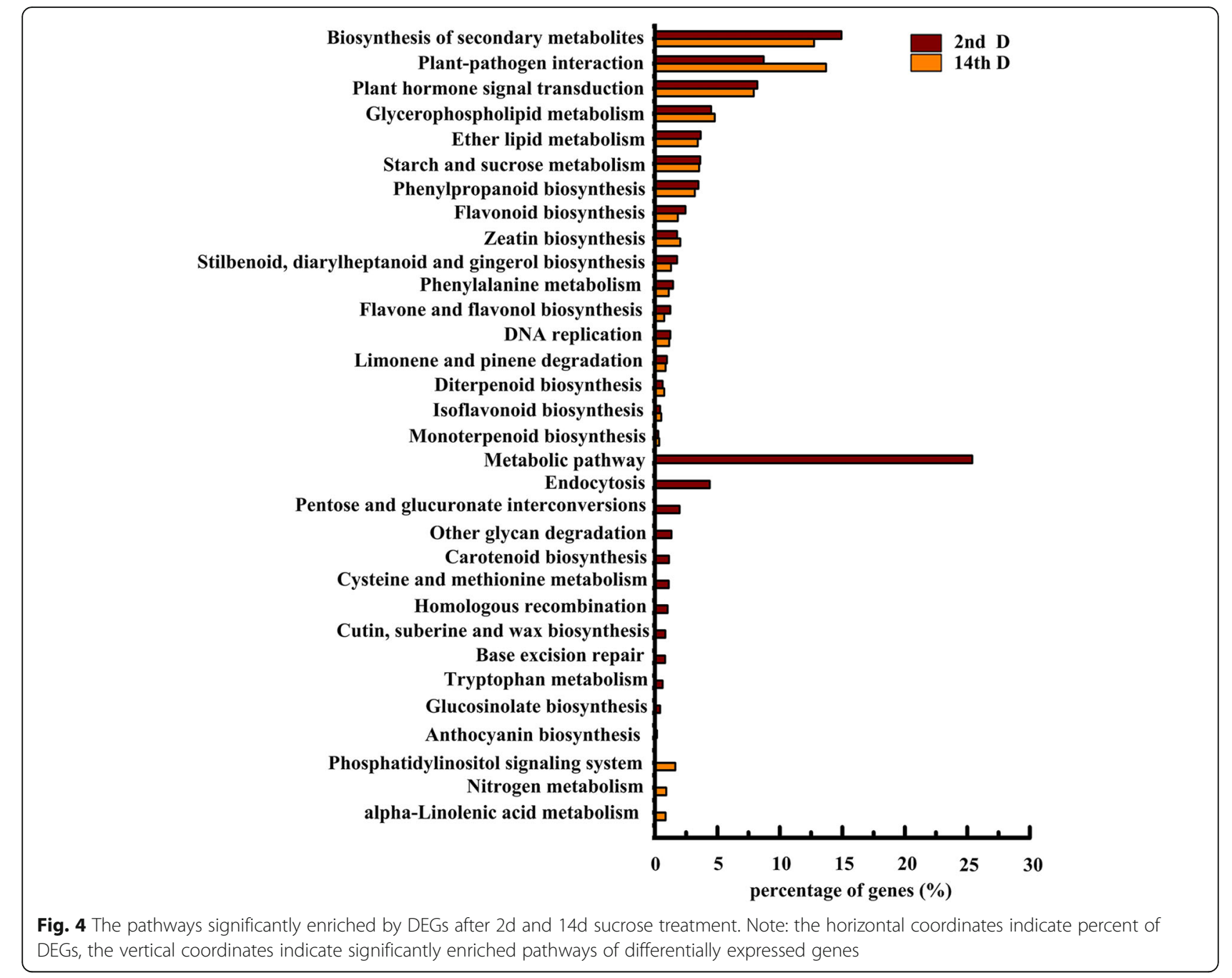

analysis showed three transcripts closely corresponding to the above 3 transporters (Fig. 7). Among them, the expression of the ABC (CL11884.Contig7) and MATE (Unigene47970) decreases significantly by sucrose after $2 \mathrm{~d}$, and their expression increases after 14d (Additional file 10: Table S6). However, the expression of the GST (Unigene24131) responds to sucrose opposite of the above mentioned two transcripts (Additional file 10: Table S6). The above results indicate there could be different transporters and GSTS for transporting the polyphenol in tea plants.

\section{Using qRT-PCR for transcriptome sequencing validation}

To validate the results of transcriptome sequencing, 30 DEGS were randomly selected to be analyzed by qRT-PCR. We found that $83.33 \%$ of the total transcripts expression was consistent with the results from transcriptome sequencing, including 11 genes involved in polyphenol biosynthesis. Detailed information regarding the selected DEGs and 11 genes is presented in Additional file 11: Figure S5.

\section{Discussion}

The mechanisms of sucrose effects on tea polyphenol biosynthesis

In the past decades, exploration of tea polyphenol biosynthesis and their influencing factors have become a hotspot for research in plant secondary metabolism [30, 43]. Due to self-incompatibility, rich genetic diversity, and the large genome in tea plants, little genomic information is available and the molecular mechanisms of tea polyphenol biosynthesis are still unclear [44, 45]. Our previous research demonstrated tea polyphenol shared a similar biosynthetic pathway to other plants, such as shikimic acid, phenylpropanoid, and flavonoids synthetic pathways [2]. Its biosynthesis is also affected by sucrose, light, and other factors $[24,46]$.

Studies have demonstrated sucrose-specific transcriptional regulation of polyphenol biosynthesis in plants. For example, Boss et al. reported that the expression of DFR involved in anthocyanin and PAs biosynthesis in grape was induced by sucrose treatment, and they speculated 


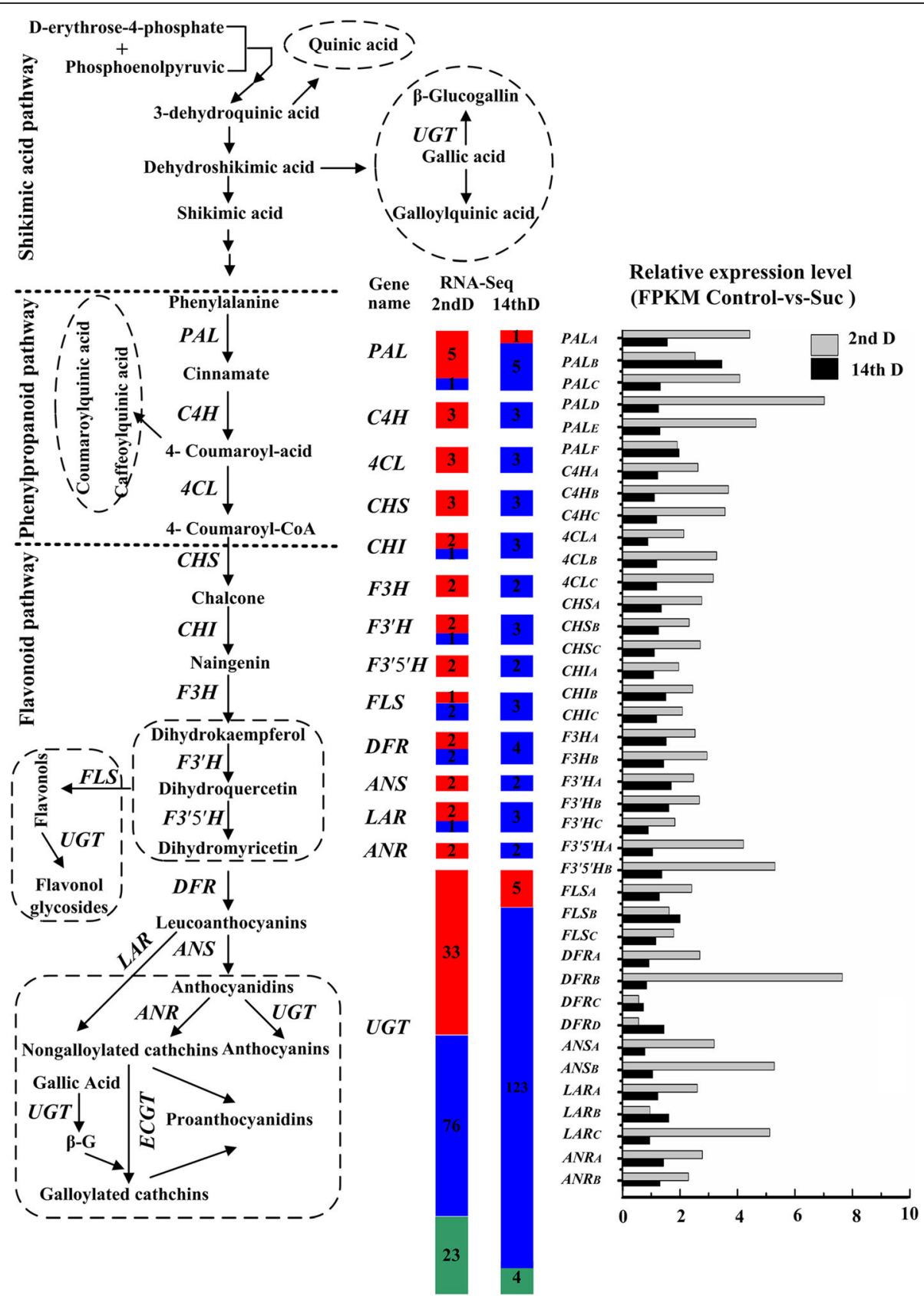

Fig. 5 Effects of sucrose on the expression of structural genes related to polyphenol biosynthesis in tea plants after $2 d$ and $14 d$. Note: Red indicates significant up-regulation, blue indicates no difference, green indicates significant down-regulation. Digit indicates the number of Unigenes

that the accumulation of the two metabolites in grape berry skin could be attributed to sugar accumulation during grape berry development [47]. According to microarray data, it was revealed that anthocyanin biosynthesis in Arabidopsisis is stimulated by sucrose which acts as a signal to activate PAP1, a TF for activating the expression of structural genes involved in anthocyanin biosynthetic pathway, such as PAL, Cinnamate 4-hydroxylase $(\mathrm{C} 4 \mathrm{H})$, 4-coumaroyl-CoA ligase (4CL), and others [19, 23]. However, the structural gene $\mathrm{F}^{\prime}{ }^{\prime}{ }^{\prime} \mathrm{H}$ and transcriptional factor
PAP2 are not affected by sucrose [19]. In tea plants, Wang et al. found the expression of Cs F3' $5^{\prime} \mathrm{H}$ increased 15-fold by feeding sucrose [25]. Liu et al. reported that sucrose induced the accumulation of catechins and upregulated the expression of putative genes involved in their biosynthetic pathway [24]. In this study, the total content of catechins and PAs significantly increases by sucrose induction for $7 \mathrm{~d}$ and the accumulation of anthocyanin increases 7-fold in the stems of tea plantlets after $14 \mathrm{~d}$ sucrose treatment. Only after $2 \mathrm{~d}$ treatment, the expression of structural genes 
Table 4 Analysis of DEGS-predicted as R2R3-MYB obtained from tea plants treated by sucrose

\begin{tabular}{|c|c|c|c|c|c|c|}
\hline Gene ID & $\begin{array}{l}\text { Gene } \\
\text { length }\end{array}$ & $\begin{array}{l}\text { 2ndD } \\
\text { fold }\end{array}$ & $\begin{array}{l}14 \text { thD } \\
\text { fold }\end{array}$ & Type & $\begin{array}{l}\text { Subgroups } \\
\text { No. }\end{array}$ & Putative function clade and gene function \\
\hline CL5525.Contig4 & 955 & $476.9^{\mathrm{a}}$ & - & R2R3 & other & Trichome development-regulated: AtMYB82 [69] \\
\hline Unigene18972 & 1084 & $17.02^{\mathrm{a}}$ & $0.41^{\mathrm{b}}$ & R1R2R3 & Unknown & \\
\hline Unigene35962 & 3506 & $13.97^{\mathrm{a}}$ & $0.49^{\mathrm{b}}$ & R1R2R3 & Unknown & \\
\hline Unigene12085 & 975 & $13.54^{\mathrm{a}}$ & $0.32^{\mathrm{b}}$ & R2R3 & 6 & Anthocyanin biosynthes-related: AtMYB75and AtMYB90 $[54,70,71]$ \\
\hline Unigene41846 & 938 & $4.98^{\mathrm{a}}$ & - & R2R3 & 6 & Secondary cell wall formation-related: AtMYB75 [72] \\
\hline Unigene35958 & 3304 & $6.28^{\mathrm{a}}$ & - & R1R2R3 & Unknown & \\
\hline CL8695.Contig1 & 1179 & $5.47^{\mathrm{a}}$ & - & R2R3 & 5 & Seed pigmentation biosynthesis -controlled: AtMYB123 [48, 73] \\
\hline Unigene11002 & 1229 & $2.93^{\mathrm{a}}$ & - & R2R3 & 5 & \\
\hline Unigene7972 & 1143 & $5.41^{\mathrm{a}}$ & - & R2R3 & 9 & Seed germination and reproductive development-related AtMYB17 $[74,75]$ \\
\hline \multirow[t]{2}{*}{ CL1441.Contig4 } & 2364 & $2.85^{\mathrm{a}}$ & - & R2R3 & 9 & Petal development: AtMYB16 [76] \\
\hline & & & & & & Repressor of cell outgrowth: AtMYB106 [77] \\
\hline Unigene24177 & 714 & $4.91^{\mathrm{a}}$ & - & R2R3 & other & \\
\hline Unigene20350 & 1829 & $2.20^{\mathrm{a}}$ & - & R2R3 & other & \\
\hline CL12359.Contig1 & 3219 & $2.56^{\mathrm{a}}$ & - & R2R3 & other & \\
\hline CL5017.Contig2 & 1322 & $4.04^{\mathrm{a}}$ & $0.34^{\mathrm{b}}$ & R2R3 & 1 & Hypersensitive response: AtMYB30Cooperates with BES1 to regulate \\
\hline CL8708.Contig1 & 1933 & $2.91^{\mathrm{a}}$ & - & R2R3 & 1 & $\begin{array}{l}\text { brassinosteroid-induced gene Expression; abiotic stress response, SA-mediated pathway } \\
\text { AtMYB30 [77] }\end{array}$ \\
\hline Unigene13855 & 767 & $3.84^{\mathrm{a}}$ & - & R2R3 & 15 & $\begin{array}{l}\text { Epidermal cell fate specification: AtMYB23 [78] } \\
\text { Trichome development: AtMYB0 and AtMYB23, }\end{array}$ \\
\hline CL7877.Contig1 & 887 & $3.25^{\mathrm{a}}$ & - & R2R3 & 15 & Root hair patterning-controlled AtMYB66 [79] \\
\hline Unigene1868 & 527 & $2.68^{\mathrm{a}}$ & - & R1 & Unknown & \\
\hline Unigene16731 & 1118 & $2.41^{\mathrm{a}}$ & - & R2R3 & 14 & Axillary meristem initiation in roots-related: AtMYB36 [80] \\
\hline CL3134.Contig13 & 4926 & $2.40^{\mathrm{a}}$ & - & R1R2R3 & Unknown & \\
\hline CL13057.Contig1 & 995 & $2.31^{\mathrm{a}}$ & - & R2R3 & 4 & The battle against UV by repressing C4H: AtMYB4 [81] \\
\hline CL13057.Contig2 & 827 & - & $2.64^{a}$ & R2R3 & 4 & \\
\hline \multirow[t]{3}{*}{ CL2339.Contig1 } & 1129 & $2.24^{\mathrm{a}}$ & - & R2R3 & 21 & Lignin, xylan and cellulose biosynthesis-regulated: AtMYB52, AtMYB54 and AtMYB69 [82] \\
\hline & & & & & & Ovule and fruit development: AtMYB117 [83] \\
\hline & & & & & & ABA hypersensitivity and drought tolerance: AtMYB52 [84] \\
\hline CL8255.Contig3 & 1314 & - & $2.02^{\mathrm{a}}$ & R2R3 & 7 & Flavonol glycosides-related: AtMYB11, AtMYB12 and AtMYB111 [34] \\
\hline CL6408.Contig3 & 1494 & $2.01^{\mathrm{a}}$ & - & R2R3 & 2 & Shoot apex morphogenesis: AtMYB13 [85] \\
\hline CL9344.Contig1 & 1068 & - & $0.25^{\mathrm{b}}$ & R2R3 & 2 & Cold stress tolerance: AtMYB14 and AtMYB15 $[86,87]$ \\
\hline CL6408.Contig1 & 1557 & - & $0.45^{\mathrm{b}}$ & R2R3 & 2 & \\
\hline CL5350.Contig2 & 1322 & - & $0.16^{\mathrm{b}}$ & R2R3 & 2 & \\
\hline Unigene48919 & 574 & $0.41^{\mathrm{b}}$ & - & R2R3 & 2 & \\
\hline CL1581.Contig2 & 1552 & - & $0.18^{\mathrm{b}}$ & R1 & Unknown & \\
\hline CL7764.Contig2 & 980 & - & $0.15^{\mathrm{b}}$ & R1 & Unknown & \\
\hline Unigene6794 & 537 & - & $2.47^{\mathrm{a}}$ & R2R3 & other & \\
\hline \multirow[t]{2}{*}{ Unigene36358 } & 1700 & - & $2.01^{\mathrm{a}}$ & R2R3 & other & AS1 leaf morphogenesis (polarity specificity) and plant immune response: AtMYB91 [88] \\
\hline & & & & & & Rough-sheath development: AtMYB91 [89] \\
\hline \multirow[t]{2}{*}{ Unigene11308 } & 1618 & - & $2.10^{\mathrm{a}}$ & R2R3 & 13 & Stomatal closure: AtMYB61 [90]; \\
\hline & & & & & & Multiple aspects of plant resource allocation-controled: AtMYB61 [91] \\
\hline \multirow[t]{2}{*}{ Unigene38120 } & 1427 & - & $0.47^{\mathrm{b}}$ & R2R3 & 22 & Stomatal closure-regulated: AtMYB44,AtMYB70, AtMYB73 and AtMYB77 [92, 93] \\
\hline & & & & & & Auxin signaling pathway- modulated: AtMYB77 [94]; \\
\hline \multirow[t]{2}{*}{ Unigene39226 } & 735 & $0.49^{b}$ & - & R2R3 & 20 & GA metabolism and signaling involved in regulation starvation responses:AtMYB62 [95]; \\
\hline & & & & & & Cell separation processes-related: AtMYB116 [96] \\
\hline Unigene2945 & 935 & $0.44^{\mathrm{b}}$ & - & R1 & Unknown & \\
\hline
\end{tabular}


Table 5 Analysis of DEGS-predicted as bHLH obtained from tea plants treated by sucrose

\begin{tabular}{|c|c|c|c|c|c|c|}
\hline GenelD & $\begin{array}{l}\text { Gene } \\
\text { length }\end{array}$ & $\begin{array}{l}\text { 2ndD } \\
\text { fold }\end{array}$ & $\begin{array}{l}14 \text { thD } \\
\text { fold }\end{array}$ & $\begin{array}{l}\text { Subfamily } \\
\text { No. }\end{array}$ & $\begin{array}{l}\text { Gene name } \\
\text { in Arabidopsis }\end{array}$ & Putative function clade and gene function \\
\hline Unigene60798 & 496 & $1967.8^{\mathrm{a}}$ & - & 3 & AtbHLH18 & \\
\hline Unigene26720 & 1512 & $15.20^{\mathrm{a}}$ & - & & AtbHLH25 & \\
\hline CL2783.Contig8 & 2320 & $280.50^{\mathrm{a}}$ & - & 25 & AtbHLH74 & Regulation root growth: AtbHLH74 [97] \\
\hline CL4342.Contig3 & 2304 & $2.02^{\mathrm{a}}$ & - & & & \\
\hline CL9935.Contig2 & 1894 & $7.50^{\mathrm{a}}$ & $0.42^{\mathrm{b}}$ & 25 & AtbHLH137 & \\
\hline Unigene21382 & 845 & $4.85^{\mathrm{a}}$ & - & 25 & AtbHLH63 & \\
\hline \multirow[t]{4}{*}{ Unigene29122 } & 545 & $8.35^{\mathrm{a}}$ & $2.14^{\mathrm{a}}$ & 1 & AtbHLH33 & Cold tolerance: AtbHLH33,AtbHLH116(ICE1),AtbHLH61and AtbHLH93 [98] \\
\hline & & & & & AtbHLH116 & Stomatal differentiation: AtbHLH33(ICE2)and AtbHLH1 16 [99]; \\
\hline & & & & & AtbHLH61 & Drought stress:AtbHLH116(ICE1) [100] \\
\hline & & & & & ,AtbHLH93 & \\
\hline CL1034.Contig1 & 3358 & - & $0.30^{\mathrm{b}}$ & 1 & AtbHLH35 & \\
\hline CL1034.Contig2 & 889 & - & $0.27^{\mathrm{b}}$ & & AtbHLH27 & Drought stress:bHLH27 [100] \\
\hline CL1034.Contig5 & 942 & - & $0.27^{\mathrm{b}}$ & & AtbHLH29 & Iron Uptake-regulated:AtBHLH29 [101] \\
\hline \multirow[t]{3}{*}{ CL1768.Contig1 } & 648 & $4.33^{\mathrm{a}}$ & - & 10 & AtbHLH57, & \\
\hline & & & & & AtbHLH67, & \\
\hline & & & & & AtbHLH70 & \\
\hline CL12543.Contig1 & 1074 & $3.58^{\mathrm{a}}$ & - & 10 & AtbHLH71 & \\
\hline CL9545.Contig2 & 1190 & $2.38^{\mathrm{a}}$ & - & 10 & AtbHLH94 & \\
\hline CL9545.Contig1 & 813 & $2.31^{a}$ & - & & AtbHLH96 & \\
\hline Unigene17438 & 326 & $2.29^{a}$ & - & & & \\
\hline CL13089.Contig1 & 2067 & $0.37^{\mathrm{b}}$ & - & 10 & AtbHLH57 & \\
\hline \multirow[t]{3}{*}{ Unigene32633 } & 1085 & $3.54^{\mathrm{b}}$ & - & 9 & AtbHLH91 & \\
\hline & & & & & AtbHLH10 & \\
\hline & & & & & AtbHLH89 & \\
\hline \multirow[t]{2}{*}{ Unigene10835 } & 1585 & $0.34^{\mathrm{b}}$ & - & 26 & AtbHLH69 & Female gametophyte development; \\
\hline & & & & & AtbHLH66 & Response to phosphate deficiency stress:AbHLH69, AbHLH66 [53] \\
\hline Unigene2520 & 732 & $2.89^{\mathrm{a}}$ & - & 16 & AtbHLH135 & \\
\hline Unigene5385 & 844 & $2.74^{\mathrm{a}}$ & - & 5 & AtbHLH42 & Anthocyanin biosynthesis (GL3, EGL3, TT8) [53] \\
\hline Unigene21617 & 2490 & $2.35^{\mathrm{a}}$ & - & & & Regulate proanthocyanidin biosynthesis $[49,51]$ \\
\hline \multirow[t]{2}{*}{ Unigene23312 } & 1076 & $2.49^{a}$ & - & 13 & AtbHLH106 & Abiotic stress-involved in cold, salt, ABA and drought stress: \\
\hline & & & & & AtbHLH107 & AtbHLH106 [102] \\
\hline Unigene47124 & 874 & $2.47 \uparrow$ & $0.43^{\mathrm{b}}$ & 27 & AtbHLH128, & \\
\hline \multirow[t]{5}{*}{ Unigene39259 } & 789 & - & $0.00^{\mathrm{b}}$ & & AtbHLH129 & Regulation root elongation and ABA response:AtbHLH129 [103] \\
\hline & & & & & AtbHLH80 & \\
\hline & & & & & AtbHLH81 & \\
\hline & & & & & AtbHLH122 & Drought and osmotic stress tolerance, ABA catabolism repression: AtbHLH122 [100] \\
\hline & & & & & AtbHLH130 & \\
\hline \multirow[t]{2}{*}{ Unigene28617 } & 886 & $2.23^{\mathrm{a}}$ & - & 15 & AtbHLH133 & \\
\hline & & & & & AtbHLH68 & \\
\hline CL8951.Contig3 & 2042 & - & $0.30^{\mathrm{b}}$ & 15 & AtbHLH123 & \\
\hline Unigene38437 & 809 & $2.20^{\mathrm{a}}$ & - & 19 & AtbHLH149 & \\
\hline CL496.Contig1 & 889 & $2.19^{a}$ & - & 31 & AtbHLH140 & \\
\hline
\end{tabular}


Table 5 Analysis of DEGS-predicted as bHLH obtained from tea plants treated by sucrose (Continued)

\begin{tabular}{|c|c|c|c|c|c|c|}
\hline GenelD & $\begin{array}{l}\text { Gene } \\
\text { length }\end{array}$ & $\begin{array}{l}2 n d D \\
\text { fold }\end{array}$ & $\begin{array}{l}14 \text { thD } \\
\text { fold }\end{array}$ & $\begin{array}{l}\text { Subfamily } \\
\text { No. }\end{array}$ & $\begin{array}{l}\text { Gene name } \\
\text { in Arabidopsis }\end{array}$ & Putative function clade and gene function \\
\hline Unigene20853 & 1750 & - & $2.87^{\mathrm{a}}$ & 31 & AtbHLH87 & $\begin{array}{l}\text { Flower and fruit development, initiation/maintenanceofaxillary } \\
\text { meristems [53] }\end{array}$ \\
\hline CL2917.Contig5 & 3168 & - & $0.28^{\mathrm{b}}$ & 2 & AtbHLH3 & Male fertility-affected:AtbHLH3(JAM3) [104] \\
\hline Unigene63328 & 1505 & - & $4.65^{\mathrm{a}}$ & 2 & AtbHLH14 & \\
\hline CL10048.Contig2 & 1395 & - & $0.05^{\mathrm{b}}$ & 7 & AtbHLH92 & Tolerance to $\mathrm{NaCl}$ and osmotic stresses: bHLH92 [105] \\
\hline CL1061.Contig1 & 2440 & - & $0.10^{\mathrm{b}}$ & 7 & AtbHLH41 & \\
\hline
\end{tabular}

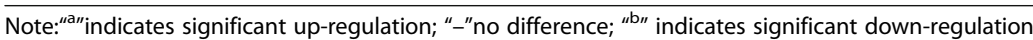

involved in their biosynthesis is up-regulated based on qRT-PCR and transcriptome sequencing. After $14 \mathrm{~d}$, the effects of sucrose were not detected.

In Arabidopsis, the correct expression of BANYULS (BAN) as a key gene of PAs biosynthesis is necessary for activation of TT2 (AtMYB123, an R2R3-MYB TF encoded by the TRANSPARENT TESTA2 gene) and TT8 (AtbHLH42, a bHLH TF encoded by the TRANSPARENT TESTA8 gene) together with TTG1 (AtTTG1, a WD-repeat protein encoded by the TRANSPARENTTESTA GLABRA1gene) [48-50]. TT2 cannot be replaced by any other AtMYB [51]. Additionally, the genes of Sg4, 5, 6, and 7 R2R3-MYB and the Subfamily2, 5, and 24 bHLH are all involved in flavonoid biosynthesis $[35,52]$. Based on their amino acid sequence alignment, it was found that 7 R2R3-MYB and 4 bHLH are predicted to participate in flavonoid biosynthesis in tea plants [53]. In the present study, seven DEGs were classified into the aforementioned four subgroups of the R2R3-MYBs and four DEGs into bHLH subfamilies 5 and 2. Among them, the expression of 3 transcripts (Unigene12085, Unigene41846, and CL8695.Contig1) in R2R3-MYB Sg6 and Sg5 were up-regulated 6-fold; this finding is consistent with those of studies indicating that sucrose can induce the expression of PAP1/ MYB75, which is essential for sucrose-induced anthocyanin biosynthesis $[19,23,48,54]$. In addition, Unigene 5385 corresponded to TT8 and its expression was significantly increased by sucrose treatment for $2 \mathrm{~d}$, indicating that it might be involved with others in regulating the accumulation of anthocyanins and PAs [55, 56]. Notably, only one transcript (Unigene25483) corresponds closely to AtTTG1, consistent with the results reported in C. sinensis [53]. However, it was not affected by sucrose, possibly because WD40 proteins have no catalytic activity and act as docking platforms for MYB and bHLH proteins in regulating flavonoid biosynthesis [48, 51, 53, 57].

As described above, it is inferred the accumulation of tea polyphenol might be directly due to high expression of their structural genes which could be synergistically regulated by TFs.
The mechanisms of sucrose effects on tea polyphenol transport

Based on analysis of UPLC-QQQ-MS/MS, the non-galloylated catechins and oligomeric PAs were significantly induced by sucrose in bud, 3rd leaf, and lower stems after 14d treatment; however, their content in upper stems decreased significantly, especially C, EC, and their oligomeric PAs. This suggests there was flavonoid transport in tea plants. Extensive research shows GST, ABC, and MATE transporters could be involved in flavonoid transport and there are at least three mechanisms, GST-linked, Vesicle trafficking (VT), and MATE transporters [38, 39, 42, 58-61]. In the present study, only three transcripts annotated as GST, $\mathrm{ABC}$, and MATE were involved in flavonoid transport, and their expression was differently affected by sucrose. As described above, it is inferred that there are varieties of proteins for synergistically transporting tea polyphenol in tea plants. However, the molecular mechanisms remain unclear.

\section{Impact of sucrose on the volatile}

It is known that the flavor of tea is basically determined by taste (non-volatile compounds) and aroma (volatile compounds) [62]. The tea polyphenol is crucial for tea taste, and the terpene derivatives including monoterpenoid and sesquiterpenoid are important aroma ingredient due to their delectable fruit fragrance and low detection threshold [63]; for example, linalool and geraniol have fruity and sweet floral scents [62]. Previous research indicated that linalool, geraniol, nerolidol, ionone, and jasmone were identified as odour-active in many types of green teas [64, 65]. In the present study, (Z)-jasmone and $\beta$-ionone content increased by 2.63 and 0.57 -fold, respectively; however, linalool, geraniol and nerolidol were not significantly affected by sucrose. As the biosynthetic pathway volatile compounds is complicated, and the molecular mechanisms involving in volatile compounds affected by sucrose need to be further studied.

\section{Conclusions}

In this paper, the test-tube tea plantlets were used for investigating the effects of sucrose on polyphenol biosynthesis. Metabolomics and transcriptomics analyses indicated 

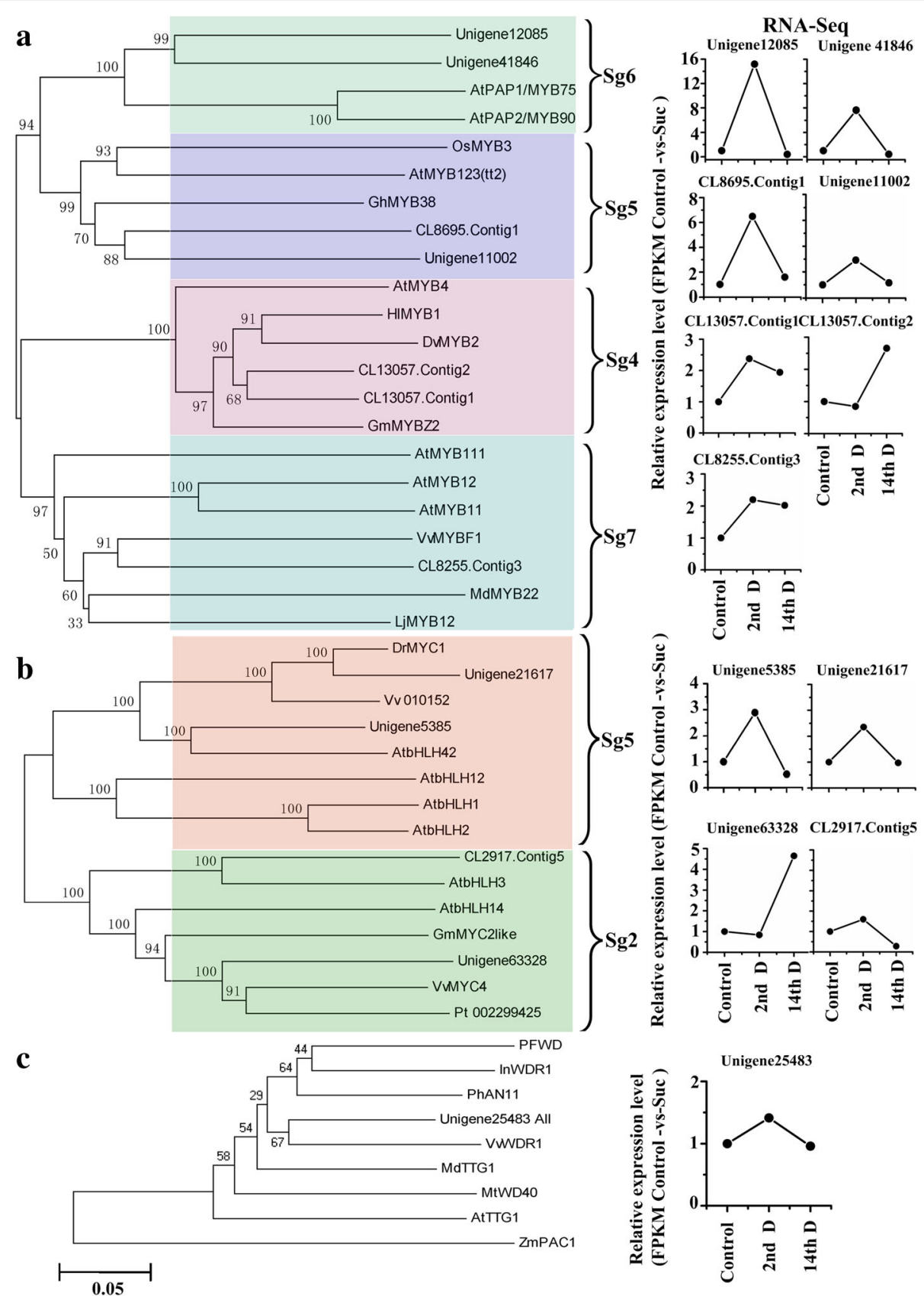

Fig. 6 Effects of sucrose on the expression of R2R3-MYB (a), bHLH (b) and WD40 (c) involved in polyphenol biosynthesis. Note: The phylogenetic tree was constructed based on amino acid sequences using MEGA5 according to the neighbor-joining method. GenBank accession numbers: MYB-Sg4: AtMYB4 (AEE86955), HIMYB1 (CAI46244), DvMYB2 (BAJ33514), GmMYBZ2 (ABI73970); MYB-Sg5: OsMYB3 (BAA23339), AtMYB123 (Q9FJA2), GhMYB38 (AAK19618); MYB-Sg6: AtMYB75 (AEE33419), AtMYB90 (AEE34503); MYB-Sg7: AtMYB11 (XP_002876680), AtMYB12 (O22264), AtMYB111 (XP_002865729), VvMYBF1 (ACV81697), MdMYB22 (AAZ20438), LjMYB12 (BAF74782), bHLH-Sg5: AtbHLH12 (Q8W2F1), AtbHLH42 (Q9FT81), AtbHLH1 (Q9FN69), AtbHLH2 (Q9CAD0), DrMYC1 (AEC03343), Vv_010152 (CAN62848.1); bHLH-Sg2: AtbHLH3 (O23487), AtbHLH14 (O23090), GmMYC2like (XP_003528771), VvMYC4 (XP_002279973), Pt_002299425 (XP_002299425). WD40: PFWD (BAB58883), InWDR (BAE94407), PhAN11 (AAC18914), VvWDR1 (NP_001268101), MdTTG1 (ADI58760), AtTTG1 (CAB45372), ZmPAC1 (AAM76742)

that sucrose up-regulation of anthocyanins, catechins, and PAs biosynthesis. Sucrose controls the expression of structural and regulating genes. Additionally, sucrose promotes the transport of polyphenol in Camellia sinensis by the predicted transporters GST, $\mathrm{ABC}$, and MATE involved in polyphenol transport. In summary, these results and analyses present valuable resources for better understanding the biosynthesis molecular mechanisms underlying the main 


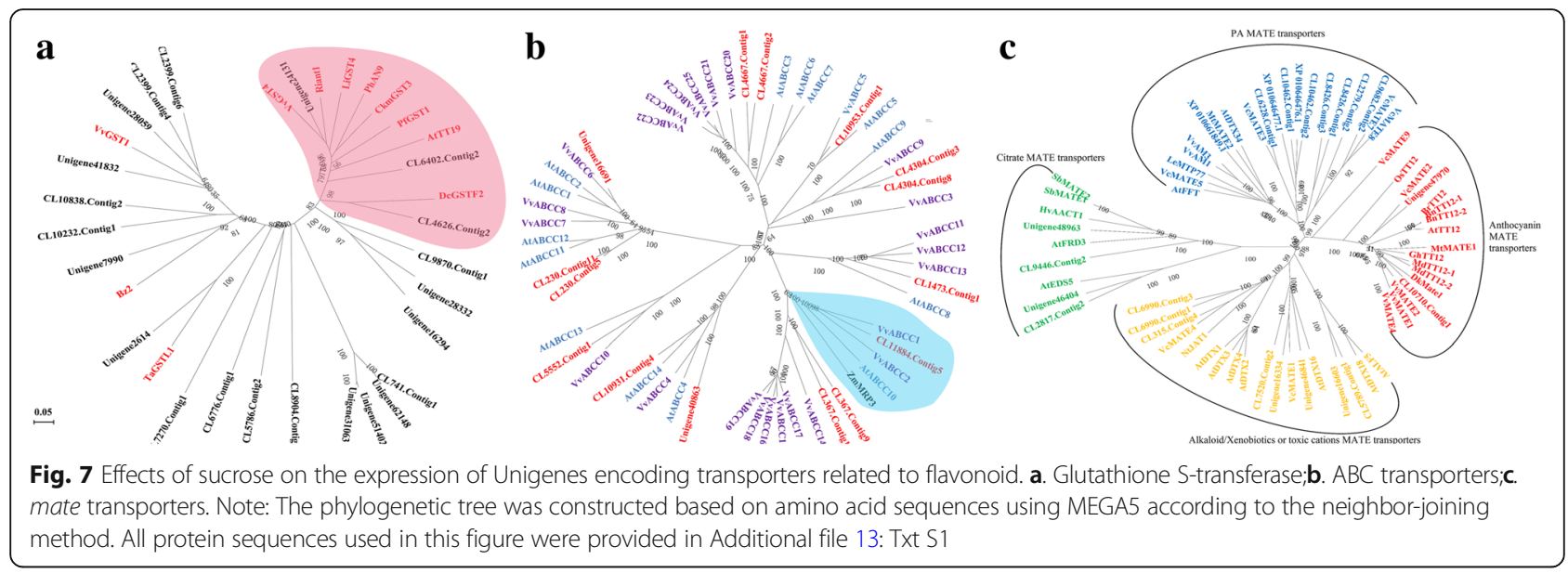

characteristics of secondary metabolites in the tea plant and help improve the nutritional quality of tea.

\section{Methods}

\section{Plant materials and cultivation conditions}

The test-tube tea plantlets [Camellia sinensis (L.) O. Kuntzevar. cultivar Nongkangzao] were initially grown in vitro on classical solid MS medium and then transferred to solid MS supplemented with $90 \mathrm{mM}$ sucrose for sucrose feeding studies with $10 \mathrm{~h}$ of light $\left(42 \mu \mathrm{mol} / \mathrm{m}^{2} \mathrm{~s}\right)$ at $24 \pm$ $1{ }^{\circ} \mathrm{C}$. Correspondingly, similar sized test-tube tea plantlets were transferred to classical solid MS medium for the control under the same conditions. In the above experiments, the tea plantlets were incubated on MS supplemented with $90 \mathrm{mM}$ mannitol for the osmotic control.

For metabolic analysis of polyphenol, the samples of different organs (the buds, third leaves, and the upper and lower stems) were collected from the tea plantlets cultivated after 2, 7, 14, and 28d. Meanwhile, samples of leaves were also collected from the tea plantlets cultivated after $2,7,14$ and $28 \mathrm{~d}$ for analysis of polyphenol biosynthesis at the transcriptional level. All the collected samples were immediately frozen in liquid nitrogen and stored at $-80^{\circ}$ Cuntil use. In this study, approximately 10 independent tea plants were collected for one biological replicate; and three biological replicates were used for analysis.

\section{Chemicals and reagents}

The compounds viz., quinic acid, $\beta$-glucogallin, galloyl acid, galloylquinic acid, caffeoylquinic acid, p-coumaroylquinic acid, catechin, epicatechin, gallocatechin, epigallocatechin, epicatechingallate, epigallocatechingallate, procyanidin $B_{2}$, myricetrin, quercitrin, and kaempferitrinwere obtained from Sigma (St Louis, MO, USA) and Axxora Co. and Ltd. (Lausanne,Switzerland). Cyanidin chloride was procured from Axxora Co. and Ltd. (Lausanne, Switzerland). HPLC grade acetic acid, methanol, and acetonitrile were bought from Tedia Co., Ltd. (Fairfield, OH, USA). Concentrated hydrochloric acid, vanillin, and other solvents used for extraction were acquired from Sinopharm Chemical Reagent Co., Ltd. (Shang-hai, China).

\section{Extraction and quantitative analysis of the polyphenol}

Extraction and quantitative analysis of the polyphenol was performed with UPLC-QQQ-MS/MS as suggested by Jiang et al. [2]. The total catechins were extracted and quantitatively analyzed using $1 \%$ vanillin- $\mathrm{HCl}(w / v)$ according to the methods described by Wang et al. [66].

Spectrophotometry analysis of anthocyanins was carried out as described by Pang et al. and the molar absorbance of cyanidin-3-O-glucoside was used for calculating the total anthocyanin concentration [67].

The total PAs were extracted and quantitatively analyzed using spectrophotometry by the methods reported by Jang et al. and their concentration was converted by using a standard curve of procyanidin $\mathrm{B}_{2}$ [2].

\section{Extraction and analysis of the volatile compounds}

Extraction and analysis of the volatile compounds collected from the samples of the leaves of tea plantlets cultivated after14 $\mathrm{d}$ were performed with a headspace-solid phase microextraction (HS-SPME) fiber, coupled with gas chromatography (Agilent 7697A) and mass spectrometry (Agilent 7890A) (GC/MS). In brief, $0.3 \mathrm{~g}$ of leaves samples were cut up and put in the $20 \mathrm{ml}$ headspace bottle $4 \mathrm{~mL}$ by adding boiling double distilled water dissolved $0.8 \mathrm{~g} \mathrm{KCl}$. After incubation for $1.5 \mathrm{~min}$, the volatile compounds were collected using a 50/30 $\mu \mathrm{m}$ DVB/CAR/PDMS SPME fiber (Supelco, PA, USA) for 50 min at $70{ }^{\circ} \mathrm{C}$ and then desorbed into the GC injection port at $250{ }^{\circ} \mathrm{C}$ for $5 \mathrm{~min}$. Subsequently, the volatile compounds were resolved by BD- 5 capillary column $(30 \mathrm{~m} \times$ $0.25 \mathrm{~mm} \times 0.25 \mu \mathrm{m}$, Agilent) for GC/MS analysis according to Han et al. [64]. 


\section{RNA extraction and qRT-PCR analysis}

Total RNA was extracted as described by Zhao et al. [53]. The RNA concentration, quality, and integrity were measured by using spectrophotometry (Agilent2100) and gel electrophoresis. The single-stranded complementary deoxyribonucleic acid (cDNA) was synthesized using Prime-Script $^{\mathrm{Tu}}$ (Takara, Dalian, Code: DRR037A) for qRT-PCR analysis. All the primer sequences were designed using Primer Premier 6.0 and the selected Unigene IDs are detailed in the additional file (see Additional file 12: Table S7). The qRT-PCR assays were performed by using a CFX96 ${ }^{\text {ma }}$ optical reaction module (Bio-RAD, USA) and the detailed detection system was the same as previously described by Zhao et al. [53]. The resultant relative expression values were normalized against the housekeeping gene glyceraldehyde-3-phosphate dehydrogenase (GAPDH) and evaluated from the mean value of three biological and three technical replicates by the $2^{-\Delta \Delta C T}$ method [68].

\section{Library construction, RNA-seq and de novo assembly}

Library Construction and de novo assembly were performed by Beijing Genome Institute (BGI; Shenzhen, China). Briefly, the specific operations are summarized as follows: the mRNA isolated from the total RNA was fragmented into smaller pieces to create templates for synthesizing the first-strand cDNA. Using the first-strand cDNA as templates, the double-stranded cDNA was produced with random primers (Japan, Takara). Subsequently, these cDNA fragments were processed by end repair using DNA polymerase and polynucleotide kinase and ligation of adapters to produce approximately 200 bp fragments. Finally, these fragments were purified by using Qiaquick Gel Extraction Kit (Qiagen) and enriched with PCR to construct cDNA libraries.

In this study, four cDNA libraries (2d: 2nd D Control and Suc; 14d: 14th D Control and Suc) were examined by using the Agilent 2100 Bioanalyzer and were sequenced using Illumina HiSeq ${ }^{\text {tw }}$ 2000. The clean reads were obtained from the raw reads by removing the low-quality reads and the reads with adaptors or unknown nucleotides larger than $5 \%$. Based on assembly of clean reads separately, Unigenes were the resulting sequences after removing redundancy and short contigs separately using the short reads assembling program-Trinity.

\section{Bioinformatics analysis of the assembled Unigenes}

By using BLASTx (E-value $10^{-5}$ ) against the database of NR, NT, GO, Swiss-Prot, COG, and KEGG, the assembled Unigenes were annotated for functional analysis and their expression levels were calculated by the fragments per $\mathrm{kb}$ per million reads (FPKM). Differentially expressed genes (DEGs) were identified with a significant threshold of $\mid \log 2$ Ratio of FPKM (Control-vs-Suc) $\mid \geq 1$ and FDR $\leq 0.001$ based on the $P$-value threshold set as $\leq 1 \mathrm{e}^{-5}$. Based on
FDR $\leq 0.05$, KEGG Pathway analysis was performed to ascertain the main biochemical and signal transduction pathways of DEGs.

\section{Phylogenetic analysis of transcription factors and transport proteins involved in polyphenols}

The phylogenetic trees for transcription factors and transport proteins were constructed according to the method as described by Zhao et al. [53]. Briefly, the MEGA 5.0 software was used for the phylogenetic analysis and the neighbor-joining statistical method was carried out based on amino acid sequences. The Bootstrap method with 1000 replicates was performed for evaluating the tree nodes. By using the p-distance method, evolutionary distances were computed. All the sequences used for the alignment were retrieved from The Arabidopsis Information Resource (TAIR, Carnegie Institution for Science Department of Plant Biology, USA), the UniProt Database (UniProt, Switzerland), and the National Center for Biotechnology Information (NCBI, USA).

\section{Availability of supporting data}

The transcriptome sequencing data based on the Illumina Hiseq 2000 platform obtained from leaves of Camellia sinensisare available in NCBI SRA (https:// www.ncbi.nlm.nih.gov/sra/ with accessions SRR5427581,SRR5427580,SRR5427578 and SRR5427577.

\section{Additional files}

Additional file 1: Table S1. Effects of sucrose on volatile compounds in leaves of tea plants using GC/ MS. Note: The data represents the mean value of three biological replications. The red indicates significant upregulation; green indicates significant down-regulation; blue indicates no difference; . Digit indicates the ratio of Suc / Control. (DOCX 40 kb)

Additional file 2: Table S2. Effects of sucrose on the expression of genes related to aroma. (DOCX $26 \mathrm{~kb}$ )

Additional file 3: Figure S1. The pathway of terpenoids biosynthesis. (TIF $412 \mathrm{~kb}$ )

Additional file 4: Table S3. Statistics of sequencing output. Note: Q20 percentage is the proportion of nucleotides with quality value larger than 20 , N percentage is proportion of unknown nucleotides in clean reads, GC percentage is proportion of guanidine and cytosine nucleotides among total nucleotides. (DOCX $20 \mathrm{~kb}$ )

Additional file 5: Table S4. Statistics of assembly quality. Note: Total Consensus Sequences represents the all assembled Unigenes, Distinct Clusters represents the cluster Unigenes; the same cluster contains some highly similar (more than 70\%) Unigenes and these may come from same gene or homologous gene, Distinct Singletons represents Unigenes from a single gene. (DOCX $21 \mathrm{~kb})$

Additional file 6: Table S5. Summary of Unigenes annotated to six databases. (DOCX $20 \mathrm{~kb}$ )

Additional file 7: Figure S2. GO functional classification of DEGs obtained from tea plants treated by sucrose after $2 d(A)$ and $14 d(B)$. Note: $\mathrm{GO}$ functions are showed on $\mathrm{X}$-axis, the right $\mathrm{Y}$-axis shows the number of DEGs which have the GO function, the left $Y$-axis shows the percentage of DEGs. (TIF $27083 \mathrm{~kb}$ ) 
Additional file 8: Figure S3. Evolutionary relationships of DEGs belong to R2R3-MYB obtained from tea plants treated by sucrose. Note: The phylogenetic tree was constructed based on amino acid sequences using MEGA5 per the neighbor-joining method, digit indicates subgroup, other indicates DEGs are not grouped. (TIF $18963 \mathrm{~kb}$ )

Additional file 9: Figure S4. Evolutionary relationships of DEGs belong to bHLH obtained from tea plants treated by sucrose. Note: The phylogenetic tree was constructed based on amino acid sequences using MEGA5 according to the neighbor-joining method, digit indicates subfamily. (TIF $16115 \mathrm{~kb})$

Additional file 10: Table S6. All expression data of contigs in Fig. 7. (XLSX $18 \mathrm{~kb}$ )

Additional file 11: Figure S5. Validation of DEGs obtained from tea plants treated by sucrose using qRT-PCR. A. DEGs obtained from tea plants treated by sucrose after 2d: B. DEGs obtained from tea plants treated by sucrose after 14d. Note: The data of qRT-PCR represents the mean value of three biological and three technical replicates. (TIF $16000 \mathrm{~kb}$ )

Additional file 12: Table S7. Primers used for QRT-PCR and detailed information regarding the selected DEGs. Note: " $\uparrow$ " indicates significant up-regulation; "-"no difference; " $\downarrow$ "indicates significant downregulation. (DOCX $39 \mathrm{~kb}$ )

Additional file 13: Txt S1. Protein sequences used in figure 7. (TXT $117 \mathrm{~kb}$ )

\begin{abstract}
Abbreviations
4CL: 4-coumaroyl-CoA ligase; ABCtransporter: ATP-binding cassette transporter; ANR: Anthocyanidin reductase; ANS: Anthocyanidinsynthase; At: Arabidopsis thaliana; C: Catechin; C4H: Cinnamate 4-hydroxylase; cDNA: Single-stranded complementary deoxyribonucleic acid; CH: Chalconeisomerase; CHS: Chalcone synthase; Cs: Camellia sinensis; DEGs: Differentially expressed genes; DFR: Dihydroflavonol 4-reductase; EC: Epicatechin; ECGT: Epicatechin:1-Ogalloyl- $\beta$-D-glucose-O-galloyltransferase; F3'5'H: Flavonoid3',5'-hydroxylase; F3' H: Flavonoid 3'-hydroxylase; F3H: Flavanone 3-hydroxylase; FDR: False discovery rate; FLS: Flavonol synthase; FPKM: Fragments per kb per million reads; GAPDH: Glyceraldehyde-3-phosphate dehydrogenase; GST: Glutathione Stransferase; LAR: Leucoanthocyanidinreductase; MATE transporter: Multidrug and toxic compound extrusion transporter; MBW: MYB-bHLH-WD40; MS: Murashige and Skoog standard medium; NGS: The next-generation sequencing; PAL: Phenylalanine ammonialyase; PAP1: Production of anthocyanin pigment 1; PAP2: Production of anthocyanin pigment 2;

PAs: Proanthocyanidins; qRT-PCR: Quantitative real-time-PCR; Sg: Subgroup; TF: Transcription factor; T12: Transparent testa 12; T19: Transparent testa19; $\Pi$ 2: Transparent testa 2; TTG1: Transparent testa glabra1; UGT: UDPGglucosyltransferase; UPLC-QQQ-MS/MS: Ultra-performance liquid chromatography-triple quadrupole mass spectrometry
\end{abstract}

\section{Acknowledgements}

We would like to thank professor Frank Obrock and Katie Fonseca for professional writing services.

\section{Funding}

This work was funded in the framework of the Natural Science Foundation of China (31570694; 31470689; 31300577). LG, the funder of NSF (31570694) and TX, the funder of NSF (31470689) and Specialized Research Fund for the Doctoral Program of Higher Education (20133418130001) conceived and supervised this study. YQ, the funder of the Natural Science Foundation for Higher Education of Anhui Province (KJ2017A441) and the Natural Science Foundation of Suzhou University (2016jb02) performed, designed the experiments and wrote the manuscript. YJL, the funder of NSF(31270730) and Natural Science Foundation of Anhui Province, China (1408085QC51) revised the manuscript. The funders of the Special Foundation for Independent Innovation of Anhui Province, China (13Z03012), the Biology Key Subject Construction of Anhui and 'Hundred Talents Program' of the Chinese Academy of Sciences(39391503-7), Anhui Major Demonstration Project for the Leading Talent Team on Tea Chemistry and Health and the Innovative Research Team in University (IRT1101) had no role in the experiment design, data analysis, decision to publish or preparation of the manuscript but supported this study.

\section{Availability of data and materials}

The datasets used and/or analyzed during the current study are available from the corresponding author on reasonable request.

\section{Authors' contributions}

TX and LG conceived and supervised this study. YQ and SZ performed the experiments and designed the experiments. SY designed the GC/MS method and analysed the date. JX and YZL analyzed the data. YQ and YJL wrote and edited this manuscript. XD participated in sample collection. XJ designed the UPLC-QQQ-MS/MS method. WW and ML performed RNA preparation. All authors read and approved the final manuscript.

\section{Competing interest}

The authors declare that they have no competing interests.

\section{Ethics approval and consent to participate}

Not applicable.

\section{Publisher's Note}

Springer Nature remains neutral with regard to jurisdictional claims in published maps and institutional affiliations.

\section{Author details}

'State Key Laboratory of Tea Plant Biology and Utilization, Anhui Agricultural University, 130 West Changjiang Rd, Hefei 230036, Anhui, China. ${ }^{2}$ School of Biological and Food Engineering, Suzhou University, 49 Middle Bianhe Rd, Suzhou 234000, Anhui, China. ${ }^{3}$ School of Life Science, Anhui Agricultural University, 130 West Changjiang Rd, Hefei 230036, Anhui, China.

Received: 18 March 2018 Accepted: 31 May 2018

Published online: 18 June 2018

\section{References}

1. Liang Y, Ma W, Lu J, Wu Y. Comparison of chemical compositions of llex latifolia thumb and Camellia sinensis L. Food Chem. 2001;75(3):339-43.

2. Jiang $X$, Liu Y, Li W, Zhao L, Meng F, Wang Y, Tan H, Yang H, Wei C, Wan X, et al. Tissue-specific, development-dependent phenolic compounds accumulation profile and gene expression pattern in tea plant [Camellia sinensis]. PLoS One. 2013;8(4):e62315

3. Winkel-Shirley B. Flavonoid biosynthesis. A colorful model for genetics, biochemistry, cell biology, and biotechnology. Plant Physiol. 2001;126(2):485-93.

4. Xia T, Gao L. Advances in biosynthesis pathways and regulation of flavonoids and Catechins. Sci Agric Sin. 2009:8:2899-908.

5. Treutter D. Significance of flavonoids in plant resistance and enhancement of their biosynthesis. Plant Biol. 2005:7(6):581-91.

6. Yang $L$, Zheng G, Liang L, Yang Y, Gao X. The research progress on pest and disease resistance of tea plant. Tea in Fujian. 2008;30(2):8-11.

7. Carmen C, Reyes A, Rafael G. Beneficial effects of green tea- a review. J Am Coll Nutr. 2006:25(2):79-99.

8. Malusà E, Russo MA. Modification of secondary metabolism and flavonoid biosynthesis under phosphate deficiency in bean roots. J Plant Nutr. 2006; 29(2):245-58.

9. Santos RMFGAC, Ferri PH, Santos SC. Influence of foliar nutrients on phenol levels in leaves of Eugenia uniflora. Rev Bras. 2011;21(4):581-6.

10. Gumerova EA, Akulov AN, Rumyantseva NI. Effect of methyl jasmonate on growth characteristics and accumulation of phenolic compounds in suspension culture of tartary buckwheat. Russ J Plant Physiol. 2015;62(2):195-203.

11. Galieni A, Mattia CD, Gregorio MD, Speca S, Mastrocola D, Pisante M, Stagnari F. Effects of nutrient deficiency and abiotic environmental stresses on yield, phenolic compounds and antiradical activity in lettuce (Lactuca sativa L.). Sci Hortic. 2015;187:93-101.

12. Wang YS, Gao LP, Shan Y, Liu YJ, Tian YW, Xia T. Influence of shade on flavonoid biosynthesis in tea (Camellia sinensis (L.) O. Kuntze). Sci Hortic. 2012;141(3):7-16.

13. Wang YS, Gao LP, Wang ZR, Liu YJ, Sun ML, Yang DQ, Wei CL, Shan Y, Xia T. Light-induced expression of genes involved in phenylpropanoid biosynthetic pathways in callus of tea ( Camellia sinensis (L.) O. Kuntze). Sci Hortic. 2012;133(1):72-83.

14. Horacio P, Martinez-Noel G. Sucrose signaling in plants: a world yet to be explored. Plant Signal Behav. 2013;8(3):e23316. 
15. Jia H, Wang Y, Sun M, Li B, Han Y, Zhao Y, Li X, Ding N, Li C, Ji W. Sucrose functions as a signal involved in the regulation of strawberry fruit development and ripening. New Phytol. 2013;198(2):453-65.

16. Boss PK, Davies C, Robinson SP. Expression of anthocyanin biosynthesis pathway genes in red and white grapes. Plant Mol Biol. 1996;32(3):565-9.

17. Larronde F, Krisa S, Decendit A, Chèze C, Deffieux G, Mérillon JM. Regulation of polyphenol production in Vitis vinifera cell suspension cultures by sugars. Plant Cell Rep. 1998;17(12):946-50.

18. Hara M, Oki K, Hoshino K, Kuboi T. Enhancement of anthocyanin biosynthesis by sugar in radish (Raphanus sativus) hypocotyl. Plant Sci. 2003;164(2):259-65.

19. Cinzia S, Alessandra P, Elena L, Amedeo A, Pierdomenico P. Sucrose-specific induction of the anthocyanin biosynthetic pathway in Arabidopsis. Plant Physiol. 2006;140(2):637-46.

20. Dubos CGJ, Baudry A, Huep G, Lanet E, Debeaujon I, Routaboul JM, Alboresi A, Weisshaar LL. MYBL2 is a new regulator of flavonoid biosynthesis in Arabidopsis thaliana. Plant J Cell Mol Biol. 2008;55(6):940-53.

21. Kyoko M, Yoshimi U, Masaru OT. AtMYBL2, a protein with a single MYB domain, acts as a negative regulator of anthocyanin biosynthesis in Arabidopsis. Plant J. 2008;55(6):954-67.

22. Smeekens S. Sugar-induced signal transduction in plants [review]. Annu Rev Plant Physiol Plant Mol Biol. 2000;51(4):49-81.

23. Teng S, Keurentjes J, Bentsink L, Koornneef M, Smeekens S. Sucrose-specific induction of anthocyanin biosynthesis in Arabidopsis requires the MYB75/ PAP1 gene. Plant Physiol. 2005;139(4):1840-52.

24. Liu Y, Wang Z, Sun M, Wang Y, Gao L, Xia T. Effect of sucrose on catechins biosynthesis in Camellia sinensis (L.) O. Kuntze. J Anhui Agricultural University. 2014;41(5):743-50.

25. Wang YS, Xu YJ, Gao LP, Yu O, Wang XZ, He XJ, Jiang XL, Liu YJ, Xia T. Functional analysis of flavonoid $3^{\prime}, 5^{\prime}$-hydroxylase from tea plant (Camellia sinensis): critical role in the accumulation of catechins. BMC Plant Biol. 2014;14:347.

26. Zhang C, Wang Y, Fu J, Dong L, Gao S, Du D. Transcriptomic analysis of cut tree peony with glucose supply using the RNA-Seq technique. Plant Cell Rep. 2014;33(1):111-29.

27. Zhang HB, Xia EH, Huang H, Jiang JJ, Liu BY, Gao LZ. De novo transcriptome assembly of the wild relative of tea tree (Camellia taliensis) and comparative analysis with tea transcriptome identified putative genes associated with tea quality and stress response. BMC Genomics. 2015;16(1):1-14.

28. Wang XC, Zhao QY, Ma CL, Zhang ZH, Cao HL, Kong YM, Yue C, Hao XY, Chen L, Ma JQ. Global transcriptome profiles of Camellia sinensis during cold acclimation. BMC Genomics. 2013;14(1):1-15.

29. Shi CY, Yang H, Wei CL, Yu O, Zhang ZZ, Jiang CJ, Sun J, Li YY, Chen Q, Xia T. Deep sequencing of the Camellia sinensis transcriptome revealed candidate genes for major metabolic pathways of tea-specific compounds. BMC Genomics. 2011;12(1):1-19.

30. Liu Y, Gao L, Liu L, Yang Q, Lu Z, Nie Z, Wang Y, Xia T. Purification and characterization of a novel Galloyltransferase involved in Catechin Galloylation in the tea plant [Camellia sinensis]. J Biol Chem. 2012;287(53):44406-17.

31. Mano H, Ogasawara F, Sato K, Higo H, Minobe Y. Isolation of a regulatory gene of anthocyanin biosynthesis in tuberous roots of purple-fleshed sweet potato. Plant Physiol. 2007;143(3):1252-68.

32. Nancy T, Laurent $T$, Agnès $A$, Sandrine V, Clotilde V, Véronique C, Charles $R$. Ectopic expression of VvMybPA2 promotes proanthocyanidin biosynthesis in grapevine and suggests additional targets in the pathway. Plant Physiol. 2009;149(2):1028-41.

33. Li M, Li Y, Guo L, Gong N, Pang Y, Jiang W, Liu Y, Jiang X, Zhao L, Wang $Y$. Functional Characterization of Tea (Camellia sinensis) MYB4a Transcription Factor Using an Integrative Approach. Frontiers in Plant Science. 2017:8:943.

34. Stracke R, Jahns O, Keck M, Tohge T, Niehaus K, Fernie AR, Weisshaar B. Analysis of PRODUCTION OF FLAVONOL GLYCOSIDES-dependent flavonol glycoside accumulation in Arabidopsis thaliana plants reveals MYB11-, MYB12-and MYB111-independent flavonol glycoside accumulation. New Phytol. 2010;188(4):985-1000.

35. Lorenzo CP, Anahit G, Irma RV, Martínez-García JF, Bilbao-Castro JR, Robertson DL. Genome-wide classification and evolutionary analysis of the bHLH family of transcription factors in Arabidopsis, poplar, rice, moss, and algae. Plant Physiol. 2010;153(3):1398-412.

36. Gonzalez A, Zhao M, Leavitt JM, Lloyd AM. Regulation of the anthocyanin biosynthetic pathway by the TTG1/bHLH/Myb transcriptional complex in Arabidopsis seedlings. Plant J. 2008;53(5):814-27.
37. Debeaujon I, Léon-Kloosterziel KM, Koornneef M. The TRANSPARENT TESTA12 gene of Arabidopsis encodes a multidrug secondary transporterlike protein required for flavonoid sequestration in vacuoles of the seed coat endothelium. Plant Cell. 2001;13(4):853-71.

38. Kitamura S, Shikazono N, Tanaka A. TRANSPARENT TESTA 19 is involved in the accumulation of both anthocyanins and proanthocyanidins in Arabidopsis. Tohoku J Agricultural Res. 2004;37(1):104-14.

39. Gomez C, Conejero G, Torregrosa L, Cheynier V, Terrier N, Ageorges A. In vivo grapevine anthocyanin transport involves vesicle-mediated trafficking and the contribution of anthoMATE transporters and GST. Plant J. 2011;67(6):960-70.

40. Francisco RM, Regalado A, Ageorges A, Burla BJ, Bassin B, Eisenach C, Zarrouk O, Vialet S, Marlin T, Chaves MM. ABCC1, an ATP binding cassette protein from grape berry, transports anthocyanidin 3-O-glucosides. Plant Cell. 2013;25(5):1840-54.

41. Marrs KA, Alfenito MR, Lloyd AM, Walbot V. A glutathione S-transferase involved in vacuolar transfer encoded by the maize gene Bronze-2. Nature. 1995:375(6530):397-400

42. Zhao J, Dixon RA. MATE transporters facilitate vacuolar uptake of epicatechin 3'-O-glucoside for proanthocyanidin biosynthesis in Medicago truncatula and Arabidopsis. Plant Cell. 2009;21(8):2323-40.

43. Jiang X, Liu Y, Wu Y, Tan H, Meng F, Ys W, Li M, Zhao L, Liu L, Qian Y, et al. Analysis of accumulation patterns and preliminary study on the condensation mechanism of proanthocyanidins in the tea plant [Camellia sinensis]. Sci Rep. 2015;5:srep08742.

44. Tanaka J, Taniguchi F, Hirai N, Yamaguchi S. Estimation of the genome size of tea (Camellia sinensis), Camellia (C. Japonica), and their interspecific hybrids by flow cytometry. Chagyo Kenkyu Hokoku. 2006;101(101):1-7.

45. Zhao DW, Yang JB, Yang SX, Kato K, Luo JP. Genetic diversity and domestication origin of tea plant Camellia taliensis (Theaceae) as revealed by microsatellite markers. BMC Plant Biol. 2014;14(1):1-12.

46. Lu Z, Liu Y, Zhao L, Jiang X, Li M, Wang Y, Xu Y, Gao L, Xia T. Effect of lowintensity white light mediated de-etiolation on the biosynthesis of polyphenols in tea seedlings. Plant Physiol Biochem. 2014;80:328-36.

47. Boss PK, Davies C, Robinson SP. Analysis of the expression of anthocyanin pathway genes in developing Vitis vinifera L. CV shiraz grape berries and the implications for pathway regulation. Plant Physiol. 1996;111(4):1059-66.

48. Nesi N, Jond C, Debeaujon I, Caboche M, Lepiniec L. The Arabidopsis TT2 gene encodes an R2R3 MYB domain protein that acts as a key determinant for proanthocyanidin accumulation in developing seed. Plant Cell. 2001; 13(9):2099-114.

49. Nesi N, Debeaujon I, Jond C, Pelletier G, Caboche M, Lepiniec L. The TT8 gene encodes a basic helix-loop-helix domain protein required for expression of DFR and BAN genes in Arabidopsis siliques. Plant Cell. 2000;12(10):1863-78.

50. Walker AR, Davison PA, Bolognesi-Winfield AC, James CM, Srinivasan N, Blundell TL, Esch JJ, Marks MD, Gray JC. The TRANSPARENT TESTA GLABRA1 locus, which regulates trichome differentiation and anthocyanin biosynthesis in Arabidopsis, encodes a WD40 repeat protein. Plant Cell. 1999;11(7):1337-49.

51. Baudry A, HM A, Bertr D, Michel C, Bernd W, Lo L. luml: TT2, TT8, and TTG1 synergistically specify the expression of BANYULS and proanthocyanidin biosynthesis in Arabidopsis thaliana. Plant J Cell Mol Biol. 2004;39(3):366-80.

52. Hichri I, Barrieu F, Bogs J, Kappel C, Delrot S, Lauvergeat V. Recent advances in the transcriptional regulation of the flavonoid biosynthetic pathway. J Exp Bot. 2011;62(8):2465-83.

53. Zhao L, Gao L, Wang H, Chen X, Wang Y, Yang H, Wei C, Wan X, Xia T. The R2R3-MYB, bHLH, WD40, and related transcription factors in flavonoid biosynthesis. Funct Integr Genomics. 2013;13(1):75-98.

54. Borevitz JO, Xia Y, Blount J, Dixon RA, Lamb C. Activation tagging identifies a conserved MYB regulator of Phenylpropanoid biosynthesis. Plant Cell. 2000;12(12):2383-94

55. Heim MA, Jakoby M, Werber M, Martin C, Weisshaar B, Bailey PC. The basic helix-loop-helix transcription factor family in plants: a genome-wide study of protein structure and functional diversity. Mol Biol Evol. 2003;20(5):735-47.

56. Baudry A, Caboche $M$, Lepiniec L. TT8 controls its own expression in a feedback regulation involving TTG1 and homologous MYB and bHLH factors, allowing a strong and cell-specific accumulation of flavonoids in Arabidopsis thaliana. Plant J. 2006;46(5):768-79.

57. Pang $Y$, Wenger JP, Katie S, Peel GJ, Wen J, Huhman D, Allen SN, Tang $Y$, Cheng X, Tadege M. A WD40 repeat protein from Medicago truncatula is necessary for tissue-specific anthocyanin and proanthocyanidin biosynthesis but not for trichome development. Plant Physiol. 2009;151(3):1114-29. 
58. Mueller LA, Goodman CD, Silady RA, Walbot V. AN9, a Petunia Glutathione S-Transferase Required for Anthocyanin Sequestration, Is a FlavonoidBinding Protein1. Plant Physiol. 2000;123(4):1561-70.

59. Goodman CD, Casati P, Walbot V. A multidrug resistance-associated protein involved in anthocyanin transport in Zea mays. Plant Cell. 2004;16(7):1812-26.

60. Narumi I, Kitamura S, Akita Y, Ishizaka H, Tanaka A. Molecular characterization of an anthocyanin-related glutathione S-transferase gene in cyclamen. J Plant Physiol. 2012;169(6):636-42.

61. Zhao J, Dixon RA. The 'ins' and 'outs' of flavonoid transport. Trends Plant Sci. 2010;15(2):72-80.

62. Ho CT, Zheng X, Li S. Tea aroma formation. Food Sci Human Wellness. 2015;4(1):9-27.

63. And CS, Schieberle P. Characterization of the key aroma compounds in the beverage prepared from Darjeeling black tea: quantitative differences between tea leaves and infusion. J Agricultural Food Chemistry. 2006;54(3):916-24.

64. Han ZX, Rana MM, Liu GF, Gao MJ, Li DX, Wu FG, Li XB, Wan XC, Wei S. Green tea flavour determinants and their changes over manufacturing processes. Food Chem. 2016;212:739-48.

65. Jumtee K, Komura H, Bamba T, Fukusaki E. Predication of Japanese green tea (Sen-cha) ranking by volatile profiling using gas chromatography mass spectrometry and multivariate analysis. J Biosci Bioeng. 2011;112(3):252-5.

66. Wang Z, Liu Y, Gao L, Xia T, Sun M. Study on the detection of Catechins in tea plant with vanillin-acid reagent. J Anhui Agricultural University. 2010; 37(4):675-81.

67. Pang Y, Peel GJ, Sharma SB, Tang Y, Dixon RA. A transcript profiling approach reveals an epicatechin-specific glucosyltransferase expressed in the seed coat of Medicago truncatula. Proc Natl Acad Sci. 2008;105(37):14210-5.

68. Livak KJ, Schmittgen TD. Analysis of relative gene expression data using realtime quantitative PCR and the $2^{-\Delta \Delta C T}$ method. Methods. 2001;25(4):402-8.

69. Liang G, Li Y, Ai Q, Yu D. MYB82 functions in regulation of trichome development in Arabidopsis. J Exp Bot. 2014;65(12):3215-23.

70. Zuluaga DL, Gonzali S, Loreti E, Pucciariello C, Degl'Innocenti E, Guidi L, Alpi A, Perata P. Arabidopsis thaliana MYB75/PAP1 transcription factor induces anthocyanin production in transgenic tomato plants. Funct Plant Biol. 2008;35(7):606-18.

71. Sun B, Zhu Z, Cao P, Hao C, Chen C, Xin Z, Mao Y, Lei J, Jiang Y, Wei M. Purple foliage coloration in tea (Camellia sinensis L.) arises from activation of the R2R3-MYB transcription factor CsAN1. Sci Rep. 2016;6:srep32534.

72. Bery A. MYB75 functions in regulation of secondary cell wall formation in the Arabidopsis inflorescence stem. Plant Physiol. 2010;154(3):1428-38.

73. Lepiniec L, Debeaujon I, Routaboul J-M, Baudry A, Pourcel L, Nesi N, Caboche M. Genetics and biochemistry of seed flavonoids. Annu Rev Plant Biol. 2006:57:405-30

74. Zhang Y, Cao G, Qu L-J, Gu H. Characterization of Arabidopsis MYB transcription factor gene AtMYB17 and its possible regulation by LEAFY and AGL15. J Genetics Genomics. 2009;36(2):99-107.

75. Pastore JJ, Limpuangthip A, Yamaguchi N, Wu M-F, Sang Y, Han S-K, Malaspina L, Chavdaroff N, Yamaguchi A, Wagner D. LATE MERISTEM IDENTITY2 acts together with LEAFY to activate APETALA1. Development. 2011;138(15):3189-98.

76. Baumann K, Perez-Rodriguez M, Bradley D, Venail J, Bailey P, Jin H, Koes R, Roberts K, Martin C. Control of cell and petal morphogenesis by R2R3 MYB transcription factors. Development. 2007;134(9):1691-701.

77. Jakoby MJ, Falkenhan D, Mader MT, Brininstool G, Wischnitzki E, Platz N, Hudson A, Hülskamp M, Larkin J, Schnittger A. Transcriptional profiling of mature Arabidopsis trichomes reveals that NOECK encodes the MIXTA-like transcriptional regulator MYB106. Plant Physiol. 2008;148(3):1583-602.

78. Kang YH, Kirik V, Hulskamp M, Nam KH, Hagely K, Lee MM, Schiefelbein J. The MYB23 gene provides a positive feedback loop for cell fate specification in the Arabidopsis root epidermis. Plant Cell. 2009;21(4):1080-94.

79. Ambawat S, Sharma P, Yadav NR, Yadav RC. MYB transcription factor genes as regulators for plant responses: an overview. Physiol Mol Biol Plants. 2013;19(3):307-21.

80. Morant M, Ekstrøm C, Ulvskov P, Kristensen C, Rudemo M, Olsen CE, Hansen J, Jørgensen K, Jørgensen B, Møller BL. Metabolomic, transcriptional, hormonal, and signaling cross-talk in superroot2. Mol Plant. 2010;3(1):192-211.

81. Jin H, Cominelli E, Bailey P, Parr A, Mehrtens F, Jones J, Tonelli C, Weisshaar B, Martin C. Transcriptional repression by AtMYB4 controls production of UV-protecting sunscreens in Arabidopsis. EMBO J. 2000;19(22):6150-61.
82. Zhong R, Lee C, Zhou J, McCarthy RL, Ye Z-H. A battery of transcription factors involved in the regulation of secondary cell wall biosynthesis in Arabidopsis. Plant Cell. 2008;20(10):2763-82.

83. Gomez MD, Urbez C, Perez-Amador MA, Carbonell J. Characterization of constricted fruit (ctf) mutant uncovers a role for AtMYB117/LOF1 in ovule and fruit development in Arabidopsis thaliana. PLoS One. 2011; 6(4):e18760.

84. Park MY, J-y K, Kim SY. Over expression of AtMYB52 confers ABA hypersensitivity and drought tolerance. Mol Cells. 2011;31(5):447-54.

85. Kirik V, Kölle K, Wohlfarth T, Miséra S, Bäumlein H. Ectopic expression of a novel MYB gene modifies the architecture of the Arabidopsis inflorescence. Plant J. 1998;13(6):729-42.

86. Chen Y, Chen Z, Kang J, Kang D, Gu H, Qin G. AtMYB14 regulates cold tolerance in Arabidopsis. Plant Mol Biol Report. 2013;31(1):87-97.

87. Agarwal M, Hao Y, Kapoor A, Dong C-H, Fujii H, Zheng X, Zhu J-K. A R2R3 type MYB transcription factor is involved in the cold regulation of CBF genes and in acquired freezing tolerance. J Biol Chem. 2006;281(49):37636-45.

88. Guo M, Thomas J, Collins G, Timmermans MC. Direct repression of KNOX loci by the ASYMMETRIC LEAVES1 complex of Arabidopsis. Plant Cell. 2008;20(1):48-58.

89. Du H, Yang S-S, Liang Z, Feng B-R, Liu L, Huang Y-B, Tang Y-X. Genomewide analysis of the MYB transcription factor superfamily in soybean. BMC Plant Biol. 2012;12:106.

90. Liang Y-K, Dubos C, Dodd IC, Holroyd GH, Hetherington AM, Campbell MM. AtMYB61, an R2R3-MYB transcription factor controlling stomatal aperture in Arabidopsis thaliana. Curr Biol. 2005;15(13):1201-6.

91. Romano JM, Dubos C, Prouse MB, Wilkins O, Hong H, Poole M, Kang KY, LI E, Douglas CJ, Western TL. AtMYB61, an R2R3-MYB transcription factor, functions as a pleiotropic regulator via a small gene network. New Phytol. 2012;195(4):774-86.

92. Albert NW, Lewis DH, Zhang H, Schwinn KE, Jameson PE, Davies KM. Members of an R2R3-MYB transcription factor family in Petunia are developmentally and environmentally regulated to control complex floral and vegetative pigmentation patterning. Plant J. 2011;65:771-84.

93. Jung C, Seo JS, Han SW, Koo YJ, Kim CH, Song SI, Nahm BH, Do Choi $Y$, Cheong J-J. Overexpression of AtMYB44 enhances stomatal closure to confer abiotic stress tolerance in transgenic Arabidopsis. Plant Physiol. 2008;146(2):623-35.

94. Shin R, Burch AY, Huppert KA, Tiwari SB, Murphy AS, Guilfoyle TJ, Schachtman DP. The Arabidopsis transcription factor MYB77 modulates auxin signal transduction. Plant Cell. 2007;19(8):2440-53.

95. Devaiah BN, Madhuvanthi R, Karthikeyan AS, Raghothama KG. Phosphate starvation responses and gibberellic acid biosynthesis are regulated by the MYB62 transcription factor in Arabidopsis. Mol Plant. 2009;2(1):43-58

96. Agustí J, Gimeno J, Merelo P, Serrano R, Cercós M, Conesa A, Talón M, Tadeo FR. Early gene expression events in the laminar abscission zone of abscission-promoted citrus leaves after a cycle of water stress/rehydration: involvement of CitbHLH1. J Exp Bot. 2012;63(17):6079-91.

97. Bao M, Bian H, Zha Y, Li F, Sun Y, Bai B, Chen Z, Wang J, Zhu M, Ning H. miR396a-mediated basic helix-loop-helix transcription factor bHLH74 repression acts as a regulator for root growth in Arabidopsis seedlings. Plant Cell Physiol. 2014;55(7):1343-53.

98. Huang X-S, Wang W, Zhang Q, Liu J-H. A basic helix-loop-helix transcription factor, PtrbHLH, of Poncirus trifoliata confers cold tolerance and modulates peroxidase-mediated scavenging of hydrogen peroxide. Plant Physiol. 2013;162(2):1178-94.

99. Kanaoka MM, Lynn Jo P, Hiroaki F, Yuki Y, Bogenschutz NL, Junji T, JianKang Z, Torii KU. SCREAM/ICE1 and SCREAM2 specify three cell-state transitional steps leading to arabidopsis stomatal differentiation. Plant Cell. 2008;20(7):1775-85.

100. Rasheed S, Bashir K, Matsui A, Tanaka M, Seki M. Transcriptomic analysis of soil-grown Arabidopsis thaliana roots and shoots in response to a drought stress. Front Plant Sci. 2016;7:180.

101. Zhang J, Zhu HF, Liang H, Liu KF, Zhang AM, Ling HQ, Wang DW. Further analysis of the function of $\mathrm{AtBHLH} 29$ in regulating the iron uptake process in Arabidopsis thaliana. J Integr Plant Biol. 2006;48(1):75-84.

102. Ahmad A, Niwa Y, Goto S, Ogawa T, Shimizu M, Suzuki A, Kobayashi K, Kobayashi H. bHLH106 integrates functions of multiple genes through their G-box to confer salt tolerance on Arabidopsis. PLoS One. 2015;10(5): e0126872. 
103. Tian H, Guo H, Dai X, Cheng Y, Zheng K, Wang X, Wang S. An ABA downregulated bHLH transcription repressor gene, bHLH129 regulates root elongation and ABA response when overexpressed in Arabidopsis. Sci Rep. 2015;5:srep17587.

104. Nakata M, Ohme-Takagi M. Two bHLH-type transcription factors, JAASSOCIATED MYC2-LIKE2 and JAM3, are transcriptional repressors and affect male fertility. Plant Signal Behav. 2013;8(12):e26473.

105. Jiang Y, Yang B, Deyholos MK. Functional characterization of the Arabidopsis bHLH92 transcription factor in abiotic stress. Mol Gen Genomics. 2009;282(5):503-16.

- fast, convenient online submission

- thorough peer review by experienced researchers in your field

- rapid publication on acceptance

- support for research data, including large and complex data types

- gold Open Access which fosters wider collaboration and increased citations

- maximum visibility for your research: over $100 \mathrm{M}$ website views per year 